\title{
Multipoint observations of transient reconnection signatures in the cusp precipitation: A Cluster-IMAGE detailed case study
}

\author{
J. M. Bosqued, ${ }^{1}$ C. P. Escoubet, ${ }^{2}$ H. U. Frey, ${ }^{3}$ M. Dunlop, ${ }^{4}$ J. Berchem, ${ }^{5}$ A. Marchaudon, ${ }^{6}$ \\ J. C. Cerisier, ${ }^{7}$ A. Fazakerley, ${ }^{6}$ E. Budnik, ${ }^{1}$ B. Lavraud, ${ }^{8}$ H. Rème, ${ }^{1}$ H. Laakso, ${ }^{2}$ \\ and A. Balogh ${ }^{9}$
}

Received 9 June 2004; revised 14 October 2004; accepted 12 January 2005; published 29 March 2005.

[1] This paper uses $90 \mathrm{~min}$ of Cluster multipoint data at $\sim 5 R_{E}$ altitude together with global dayside imaging data provided by the IMAGE-SI-12 instrument to analyze the northern cusp crossed on 14 July 2001, during a period of high solar wind pressure $P_{s w}$ and strongly duskward interplanetary magnetic field (IMF). Simultaneous observations reveal intense cusp activity in the postnoon sector, characterized by multiple, impulsive energy-dispersed ion injections, with a recurrence time of $\sim 8-10 \mathrm{~min}$ or less. Most of these transient signatures correspond one to one with repeated $P_{s w}$ enhancements. A multipoint analysis reveals that field-aligned current sheets associated with ion steps are moving predominantly westward with a velocity, up to $\sim 20 \mathrm{~km} / \mathrm{s}$, in agreement with a flux tube motion controlled by magnetic tension forces when IMF $B_{y} \gg 0$. These data are used to infer a source region located at $\sim 7-13 R_{E}$ from Cluster, that is, on the dusk flank of the compressed magnetosphere, around 1718 magnetic local time. We interpret these very dynamic and transient features as probable signatures of pulsed magnetic reconnection that is operating in a localized region of the magnetopause centered in the preferential antiparallel merging site. Our results suggest that the reconnection rate is not spontaneously self-varying but may be directly modulated by either upstream dynamic pressure $P_{s w}$ or changes in the IMF polarity.

Citation: Bosqued, J. M., et al. (2005), Multipoint observations of transient reconnection signatures in the cusp precipitation: A Cluster-IMAGE detailed case study, J. Geophys. Res., 110, A03219, doi:10.1029/2004JA010621.

\section{Introduction}

[2] Originally introduced by Dungey [1961] in his pioneering open model, the concept of magnetic reconnection between the interplanetary magnetic field (IMF) and the

\footnotetext{
${ }^{1}$ Centre d'Etude Spatiale des Rayonnements, Centre National de la Recherche Scientifique, Toulouse, France.

${ }^{2}$ European Space Research and Technology Centre, Space Science Department, European Space Agency, Noordwijk, Netherlands.

${ }^{3}$ Space Sciences Laboratory, University of California, Berkeley, California, USA.

${ }^{4}$ Space Science and Technology Department, Rutherford Appleton Laboratory, Chilton, Didcot, UK.

${ }^{5}$ Institute of Geophysics and Planetary Physics, University of California, Los Angeles, California, USA.

${ }^{6}$ Mullard Space Science Laboratory, University College London, Dorking, UK

${ }^{7}$ Centre d'Etude des Environnements Terrestre et Planétaires, SaintMaur-des-Fossés, France.

${ }^{8}$ Space and Atmospheric Sciences, Los Alamos National Laboratory, Los Alamos, New Mexico, USA.

${ }^{9}$ Space and Atmospheric Physics Group, Blackett Laboratory, Imperial College, London, UK.

Copyright 2005 by the American Geophysical Union. 0148-0227/05/2004JA010621
}

Earth's magnetic field has crucially influenced the interpretation of more than four decades of observations and theoretical studies of the magnetosphere. Challenges of this early view of a quasi-steady reconnection came first for high latitudes, on the basis of HEOS-2 data [Haerendel et al., 1978] and, then for lower latitudes, on the basis of the first dual-satellite observations of ISEE 1 and 2, and the discovery of transient signatures of reconnection, or flux transfer events (FTEs) [Russell and Elphic, 1978, 1979]. FTEs, which occur on the dayside magnetopause, are considered as the most direct evidence of a patchy magnetic reconnection. Since their discovery a great number of statistical studies have been performed to characterize their local properties at the magnetopause (see review by Elphic [1995]).

[3] Signatures have been searched in different regions directly connected with the dayside magnetopause, from the high-altitude cusp to the ionosphere. For southward IMF, particle observations at various altitudes have shown, not only classical cusp ion energy dispersions [Reiff et al., 1977; Escoubet and Bosqued, 1989; Bosqued et al., 1991], but also abrupt discontinuities in ion energy dispersion; these have sawtooth profiles [Lockwood and Davis, 1996], "staircase" or ion step shapes [Newell and Meng, 1991; Escoubet 
et al., 1992; Lockwood and Smith, 1992], or have opposite dispersions [Escoubet et al., 1997]. Temporal variations in the reconnection rate have been often invoked to explain these discontinuities, and a number of modeling efforts based on pulsating reconnection have been successful in predicting the existence of stepped precipitation [Lockwood et al., 1998, and references therein]. Nevertheless, cusp ion steps or discontinuities could be a spatial effect. Lockwood [1995] reviewed experimental evidences and proposed that steady reconnection at two (or more) isolated $X$ lines may generate major neighboring flux tubes that evolve with different time histories. This scenario was supported by conjugate interspacecraft comparisons [Trattner et al., 2002, 2003]. However, even in these observations, many smaller structures were observed within major structures, and these could constitute expected signatures of reconnection pulses at the $X$ line. Recently, "double" spatial cusps, as opposed to temporal, were observed and modeled by Wing et al. [2001]. Adjacent, double dispersion ramps, can be successively crossed in case of favorable antiparallel merging conditions, that is, conditions in which the IMF $B_{y}$ component dominates $\left(\left|B_{y}\right| \gg\left|B_{z}\right|\right)$.

[4] In the dayside ionosphere, a rich variety of signatures was also found for a southward pointing IMF; the most clear, poleward moving, transient, auroral forms (PMAFs) were detected independently or simultaneously by groundbased instruments, incoherent and HF coherent radars, optical photometers (630 and $557.7 \mathrm{~nm}$ ), and global UV imaging [Milan et al., 2000, and references therein; Sandholt and Farrugia, 2003, and references therein]. Their observed dawnward (duskward) motion when IMF $B_{y}>0$ $(<0)$ in the northern hemisphere demonstrated that they are the probable ionospheric footprint signatures of newly reconnected flux tubes moving, as predicted, in response to 'tension' forces. Among these ionospheric studies, few noted the striking correlation between the recurrence of cusp transients and the arrival at Earth of solar wind dynamic pressure pulses [Sandholt et al., 1994; Farrugia et al., 1995]. Solar wind pressure changes may play a role in generating FTE-like structures [Elphic, 1988; Sibeck, 1992, and references therein]. Expectations of FTE-like signatures driven by pressure pulses resulting in subsequent surface waves on the magnetopause were discussed by Sibeck [1990] and Lockwood [1991]. The generation of flux transfer events by pressure pulses remains a controversial topic [Song et al., 1994], especially since reconnection could itself generate, as a byproduct, surface waves [Biernat et al., 1998]. Another difficulty lies in determining the correct plasma parameters that occur near the magnetopause. Thus, whether FTE signatures are caused by quasicontinuous reconnection, or patchy/transient reconnection (in a single or multiple sites), or by wavy magnetopause motion induced by solar wind pressure increases, remains open to investigation.

[5] Since January 2001 the unprecedented multispacecraft Cluster mission in the dayside cusp have provided a unique opportunity to address these questions. The first correlated Cluster ground-based measurements revealed up-to-date and convincing relationships between the patchy FTEs observed at the magnetopause, cusp motions, "pulsed ionospheric flows" (PIFs), and "poleward moving radar auroral forms" (PMRAFs) in the conjugate ionosphere [Lockwood et al., 2001a, 2001b; Wild et al., 2001], and, for the first time, in the two conjugate hemispheres [Wild et al., 2003]. These first studies confirmed the temporal nature of the reconnection process [Bosqued et al., 2001; Lockwood et al., 2001a, 2001b; Opgenoorth et al., 2001; Vontrat-Reberac et al., 2003] and, in some cases, its spatial nature [Trattner et al., 2003; Lavraud et al., 2005]. They have also demonstrated the importance of a multispacecraft approach [Wild et al., 2005], coordinated observations from ground-based instruments [Farrugia et al., 2004; Marchaudon et al., 2004], in-space global imaging [Frey et al., 2003a], and global simulations [Berchem et al., 2003a, and references therein]. During the 2001 summer period Cluster crossed the midaltitude cusp at 5-6 $R_{E}$ altitude. In an elongated tetrahedron configuration, three spacecraft were separated by $\sim 2000 \mathrm{~km}$, and the last one, SC3, lagged behind at $\sim 10,000 \mathrm{~km}$, that is, $40-50 \mathrm{~min}$. The multiple spacecraft cusp crossing allowed data collection for extended (60$90 \mathrm{~min}$ ) and overlapping intervals. One of the main difficulties was finding 40-90 min periods of a fairly stable solar wind and IMF conditions required for avoiding or minimizing changes in cusp structures that result from changes in the location of the $X$ line. This paper uses the 14 July 2001 event to present one of the first, simultaneous, cusp observations made in situ at midaltitude (4-6 $R_{E}$ ), by Cluster, and in the conjugate ionosphere by the IMAGE spacecraft. During the period under study, for $\sim 30$ min a very high density, cold, solar wind structure passed the Earth, followed by a hotter, less dense solar wind. During the entire period the magnetic field had a southward IMF together with a strong duskward component. We take advantage of this period of a high solar wind dynamic pressure $\left(P_{s w}>5 \mathrm{nPa}\right)$ to examine the influence of pressure changes on midaltitude and low-altitude signatures. In particular, we address the question of whether, and how, pressure pulses in the solar wind/magnetosheath trigger transient reconnection events and cause the ion injections observed at midaltitude and low altitudes.

[6] This paper's organization includes in section 2 a brief description of the Cluster instruments and IMAGE/ FUV/SI-12 instrument. Section 3 presents the prevailing interplanetary conditions, and section 4 presents the observations in two parts. Cluster/CIS multipoint data are surveyed in section 4.1 and data from IMAGE are analyzed in section 4.2. A quantitative comparison between the two CIS/ FUV data sets starts the discussion in section 5 , followed by an analysis of reconnection processes in a 4-min period; finally, section 5 discusses dynamic pressure effects.

\section{Instrumentation and Orbit}

\subsection{Cluster Orbit and Instrumentation}

[7] The Cluster mission is supported by four identical spacecraft, launched in pairs in July and August 2000. They move in a tetrahedral formation with adaptable interspacecraft distances, ranging from $\sim 100 \mathrm{~km}$ to a few $R_{E}$. Cluster is located on an elliptical orbit with a perigee of $4 R_{E}$, an apogee of $19.6 R_{E}$, a period of $\sim 58 \mathrm{~h}$, and an inclination of $90^{\circ}$. During summer 2001 and near the dayside perigee, the Cluster tetrahedron was in a specific configuration and the spacecraft were strung out in a line along the outbound orbit in the northern cusp, with SC4 in the lead, followed by SC2 


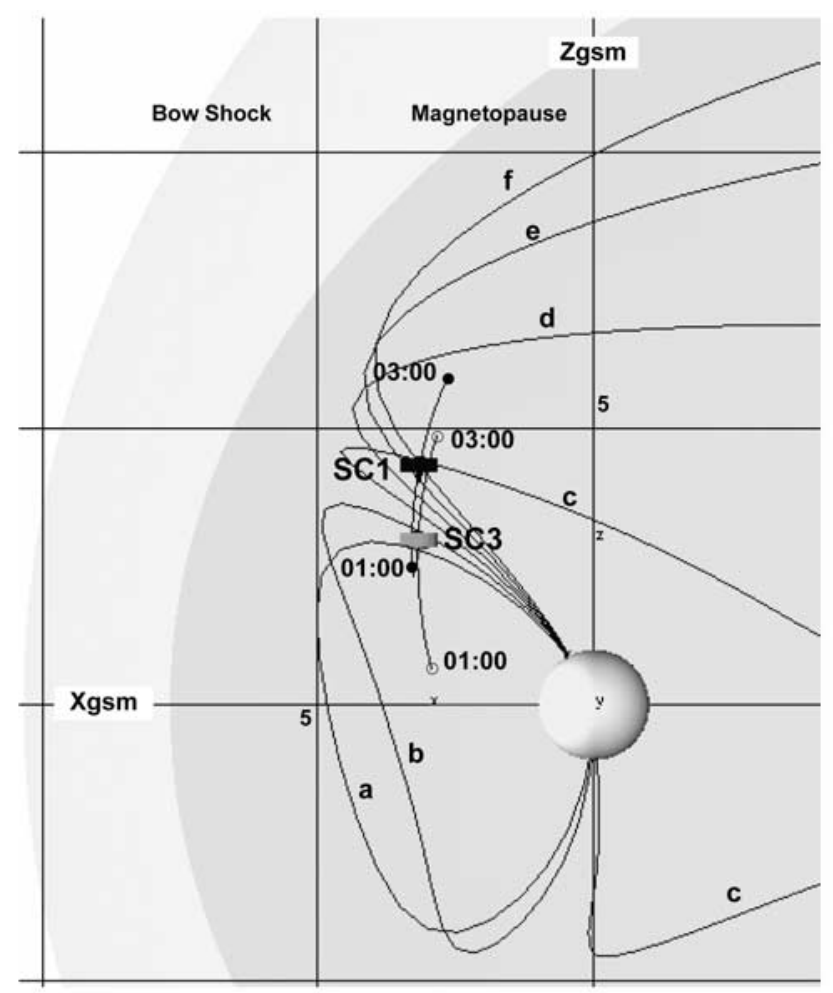

Figure 1. Dayside magnetosphere and Cluster SC3/SC1 orbits on 14 July 2001 during the interval 0100-0300 UT, viewed from the $+Y_{G S M}$ direction. The SC1 and SC3 positions are given at 0200 UT. Six field lines successively intercepted by $\mathrm{SC} 1$ are displayed every $10 \mathrm{~min}$, from 0120 UT (line a) to 0200 UT (line f). The field lines were computed using the T-01 (+IGRF) model for IMF $=[-8$, $+5,0)]_{\mathrm{GSM}}$ and $P_{s w}=10 \mathrm{nPa}$.

and SC1, and finally by SC3. Successive separations at 0130 UT and $\sim 5 R_{E}$ altitude were $d_{42} \sim 1165 \mathrm{~km}\left(\Delta T_{42} \sim\right.$ $4 \mathrm{~min}), d_{41} \sim 2307 \mathrm{~km}\left(\Delta T_{41} \sim 8 \mathrm{~min}\right), d_{43} \sim 11982 \mathrm{~km}$ $\left(\Delta T_{43} \sim 43-49 \mathrm{~min}\right)$, and the successive orbits tracks mapped to the postnoon ionosphere were roughly superposed $\left(73.5^{\circ}-74^{\circ}\right.$ at $\sim 13.7$ magnetic local time (MLT)). These separations were well suited for a cusp study on timescales ranging from $2-10 \mathrm{~min}$ to as long as $50 \mathrm{~min}$. The SC1 and SC3 orbits are indicated schematically in Figure 1.

[8] In this paper we use particle data provided by the Cluster Ion Spectrometers, CIS, fully described by Rème et al. [2001], and the Plasma Electron and Current Experiment (PEACE) [Johnstone et al., 1997]. Magnetic field data come from the Fluxgate Magnetometers (FGM) [Balogh et al., 2001], and the electric field data from the Electric Field and Wave (EFW) instrument [Gustafsson et al., 2001]. As a result of an unidentified electronic failure, both CIS instruments on Cluster spacecraft SC2 were switched off. The observations presented in this study include the CIS-2/HIA data from spacecraft SC1 and SC3 and the CIS-1/CODIF data from spacecraft SC4 (CIS-2/HIA was switched off on SC4).

\subsection{IMAGE/FUV}

[9] Launched in 2000, the IMAGE satellite moves in an elliptical orbit at altitudes of $1000-45,000 \mathrm{~km}$. The Far
Ultra-Violet imager (FUV) consists of three imaging instruments that take measurements of the aurora for 5-10 s every 2 min of the spin period [Mende et al., 2000; Frey et al., 2001, 2003b]. Data presented in this paper were collected by the proton aurora imaging Spectrographic Imager channel (SI-12) which senses Doppler-shifted Lyman $\alpha$ emissions around $121.8 \mathrm{~nm}$ that result from charge-exchanging precipitating protons. It is most sensitive to proton precipitation in the energy range of $2-8 \mathrm{keV}$, and has very low sensitivity below $1.5 \mathrm{keV}$ [Gérard et al., 2000, 2001].

\section{Interplanetary Conditions}

[10] The interplanetary prevailing conditions during the period of study (IMF and solar wind plasma parameters) were obtained from the ACE spacecraft. ACE was located near the L1 Lagrangian point at $\left(X=1.59 \times 10^{6}, Y=11742\right.$, $Z=140374)_{G S M} \mathrm{~km}$ around 0030 UT. Figure 2 shows observations from the time period $0115-0245$ UT. The first four panels of Figure 2 show the IMF $B_{x}, B_{y}$, and $B_{z}$ components, followed by the IMF clock angle defined by: $\theta_{\mathrm{IMF}}=\tan ^{-1}\left(\left|B_{y}\right| / B_{z}\right)_{G S M}$. In the fifth through eighth panels of Figure 2 are plotted the solar wind parameters: dynamic pressure, ion temperature, velocity, and number density. The last panel of Figure 2 displays the magnetic field strength measured by the Polar spacecraft, in the dawnside of the magnetosphere.

[11] It is crucial to know the precise time required for the solar wind to propagate from the ACE spacecraft to the magnetosphere. We estimated this time delay with two different, but complementary, methods. First, we computed the total estimated delay given by Jacobsen et al. [1995], which depends on the exact ACE position (note that ACE is off the $(X-Y)_{\mathrm{GSM}}$ plane), and assume that the IMF components remain constant between ACE and the bow shock. With this approach, the total propagation time from ACE to Cluster depends on the IMF polarity and the solar wind velocity, and therefore changes during the event. For instance, at $0140 \mathrm{UT}$, the total time lag is $\sim 55-57 \mathrm{~min}$, but it is only $50-52 \mathrm{~min}$ at $0156 \mathrm{UT}$. Second, to determine this time more precisely, we used the observed delays between the pressure changes at ACE and the associated effects seen at geostationary orbits or near the Polar spacecraft. Polar was near its equatorial apogee in the dawn sector $(X=+0.69, Y=-8.50, Z=3.50)_{G S M} R_{E}$, and we assumed that after the pressure bubble hits the magnetosphere, variations in the compressed geomagnetic field at Polar followed. From the Polar magnetic strength profile (Figure 2, last panel) for 0125 to 0215 UT we deduced that the time lag between ACE and Polar varied from 53 to $58 \mathrm{~min}$ and was $\sim 1$ min greater than the time lag between ACE and Cluster, at $\sim 5 R_{E}$ altitude on the dayside. The time delays finally adopted are given in the central part of Figure 2, between the $P_{s w}$ and $\theta_{I M F}$ plots. Delays are $57 \mathrm{~min}$ before $0148 \mathrm{UT}, 55 \mathrm{~min}$ between 0148 and $0152 \mathrm{UT}, 52 \mathrm{~min}$ between 0152 and 0203 UT, 55 min between 0203 and 0215 UT, and back to $57 \mathrm{~min}$ after $0215 \mathrm{UT}$. These convection delay times may be off by 1-2 min and could be estimated more exactly for shorter time intervals. Nevertheless, they are compellingly confirmed by the observed magnetic compression effects at GOES10 on the equatorial dusk side (not 


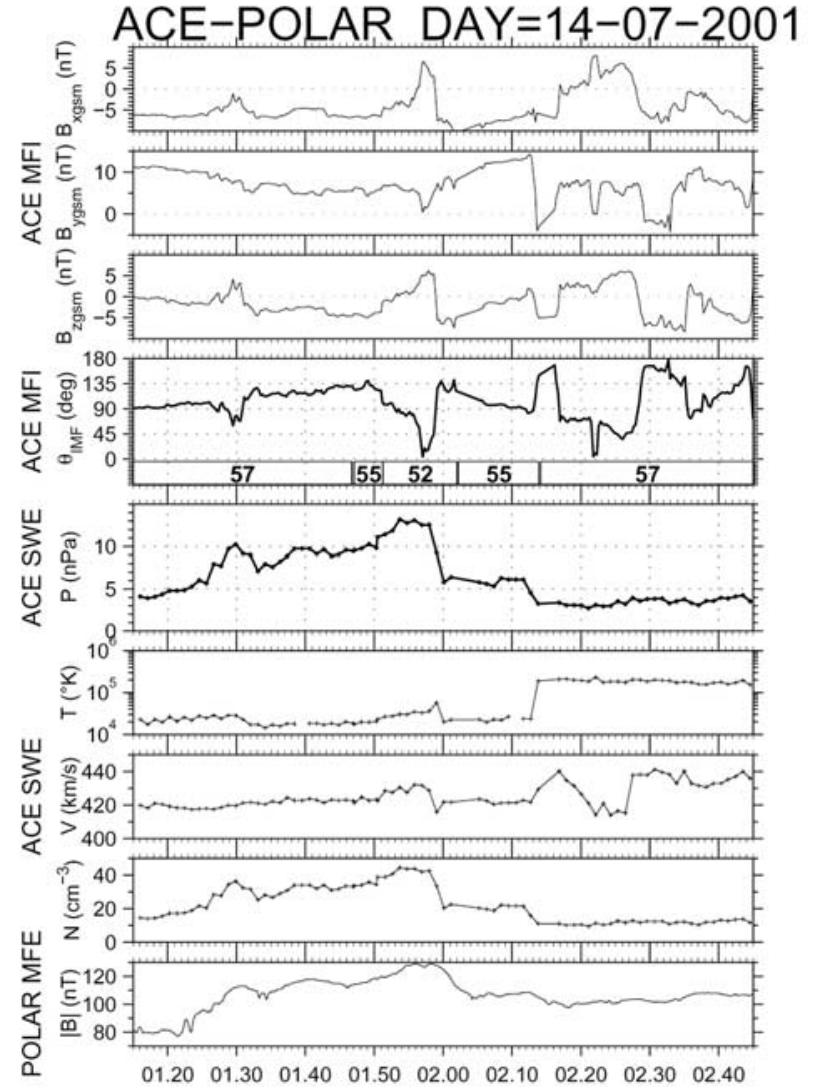

Figure 2. Upstream interplanetary magnetic field and solar wind parameters detected by $\mathrm{ACE} / \mathrm{MFI}$ and ACE/ SWEPAM instruments and Polar magnetic field by the Polar/MFE instrument, on 14 July 2001, for the interval 0115-0245 UT. Plotted from top to bottom are the three magnetic field components IMF $B_{x}, B_{y}$, and $B_{z}$ (nT, GSM coordinates); the $\theta_{\mathrm{IMF}}$ clock angle; the solar wind dynamic pressure $P_{s w}(\mathrm{nPa})$; the ion temperature $T_{i}\left({ }^{\circ} \mathrm{K}\right)$; the magnitude of the solar wind velocity $V_{s w}(\mathrm{~km} / \mathrm{s})$; and the number density $N_{i}\left(\mathrm{~cm}^{-3}\right)$. The last panel gives the magnetic field strength $|B|(\mathrm{nT})$ measured by Polar/MFE. To allow for the propagation time between ACE and Cluster, all the upstream ACE data were adjusted by a travel time that varied from $\sim 52$ to $\sim 57 \mathrm{~min}$; successive time delays are given between the plots of $P_{s w}$ and $\theta_{\mathrm{IMF}}$.

shown). Moreover, on the magnetospheric dawnside, as a result of an inward motion of the magnetopause, Geotail made a short excursion in a very high density magnetosheath around $0154-0156 \mathrm{UT}$, which is strongly correlated to the time-lagged pressure maximum.
[12] The solar wind dynamic pressure variations during this $80 \mathrm{~min}$ period were very significant. Until $0120 \mathrm{UT}$, the dynamic pressure $P_{s w}$ remained quite constant at $\sim 4 \mathrm{nPa}$ (density $\sim 13 \mathrm{~cm}^{-3}$ ), which is slightly higher than the typical solar wind pressure. Then at $\sim 0125$ UT $P_{s w}$ suddenly increased by about a factor of 2 . A second peak was observed at $\sim 0140 \mathrm{UT}$, after which the dynamic pressure increased to a maximum of $\sim 13 \mathrm{nPa}$ at $\sim 0152$ UT. Finally, after $0158 \mathrm{UT}$, the pressure dropped to an intermediate value of $\sim 6 \mathrm{nPa}$, and then returned to its pre-event level of $\sim 3 \mathrm{nPa}$. The empirical model of Shue et al. [1998] gives the standoff distance of the magnetopause as a function of IMF $B_{z}$ and the solar wind dynamic pressure. At 0120 UT the subsolar magnetopause was already compressed $\left(P_{s w} \sim 4 \mathrm{nPa}\right)$ to $\sim 9.24 R_{E}$. An increase in compression started at $\sim 0125$ UT and the closest subsolar standoff distance jumped to about $7.25 R_{E}$ at $0155 \mathrm{UT}$ according to ACE data, and even $6.57 R_{E}$ according to the pressure value given by Wind ( $\sim 25 \mathrm{nPa}$, but at $\sim 250 R_{E}$ in the $+Y_{G S M}$ direction).

[13] The IMF $B_{z}$ component changed to negative at $\sim 0118$ UT, the beginning of the interval of interest, and reached $-5 \mathrm{nT}$, experiencing only short northward turnings, concurrent with the larger pressure jump (0154-0159 UT), and with the first jump, between 0128 and 0131 UT. The $B_{x}$ component remained negative $(\sim-5 /-10 \mathrm{nT})$ except when the $B_{z}$ component was positive. For most of the event the $B_{y}$ component remained largely positive, and returned to $\sim 0$ for short intervals after 0213 UT.

\section{Overview of Satellite Data}

\subsection{Cluster Data}

[14] Figure 3a shows combined ion data from CIS instruments onboard Cluster spacecraft SC1, SC3, and SC4 for the interval $0115-0245$ UT on 14 July 2001 . One colorcoded panel for each spacecraft (top, SC4; middle, SC1; and bottom, SC3) displays the spectrogram of downward moving ions (pitch angle within $40^{\circ}$ of the downward fieldaligned direction). Successive ion injections are referenced in chronological order by the $\mathrm{t} 1, \mathrm{t} 2, \ldots, \mathrm{t} 10$ vertical marks. The $P_{s w}$ and IMF $B_{z}$ ad hoc (time-lagged) profiles are displayed for reference at the top of Figure 3a.

[15] At $\sim 0117$ UT $\left(71.87^{\circ}\right.$ magnetic latitude (MLAT), 14.39 MLT), the poleward moving spacecraft SC4 was the first of the three to cross the OCB (Open-Closed Boundary) defined by the poleward drop-off in the flux of high-energy trapped electrons (not shown), jointly provided by the RAPID instrument $\left(E_{e}>95 \mathrm{keV}\right.$, courtesy M. Carter) and the PEACE instrument $\left(E_{e}>10 \mathrm{keV}\right)$. As it moved poleward, the SC4/CIS-1 instrument detected three successive major injections of $\mathrm{H}^{+}$ions at $\sim 0119: 30$ UT

Figure 3. Cluster CIS plasma data from the spacecraft SC4, SC1, and SC3, for the time interval 0115-0245 UT, on 14 July 2001. Data from SC4 were recorded by the CIS1(CODIF) instrument $\left(\mathrm{H}^{+}\right.$channel), while data from $\mathrm{SC} 1$ and SC3 were recorded by the CIS2(HIA) instruments. The time resolution is $12 \mathrm{~s}$. Superimposed as vertical blue guidelines are the times (labeled t1, ..t10) of the main ion injections, in chronological order. (a) Reference, time-lagged IMF $B_{z}$ and $P_{s w}$ parameters and ion energy-time spectrograms for each spacecraft giving the differential energy flux $\left(\mathrm{keV}\left(\mathrm{cm}^{2} \mathrm{~s} \mathrm{keV}\right)^{-1}\right)$ for precipitating ions (pitch angle range $0^{\circ}-40^{\circ}$ ) and the associated $(X, Y, Z)_{\mathrm{GSM}} R_{E}$ and MLT and MLAT coordinates (MLT is expressed in hours and fraction of an hour). (b) CIS plasma data plotted as a function of MLAT, from $71^{\circ}$ to $76.5^{\circ}$ MLAT. SC4, SC1, and SC3 spacecraft crossed $72^{\circ}$ MLAT at 0119:03, 0124:46, and 0206:00 UT, respectively, and $76^{\circ}$ MLAT at 0151:22, 0206:00, and 0240:17 UT, respectively. For each spacecraft is plotted the energy-latitude spectrogram of upward moving ions (pitch angle $=140^{\circ}-180^{\circ}$ ). Red bar above each panel indicates the high-latitude boundary layer. 


\section{CLUSTER-CIS 14-07-2001}
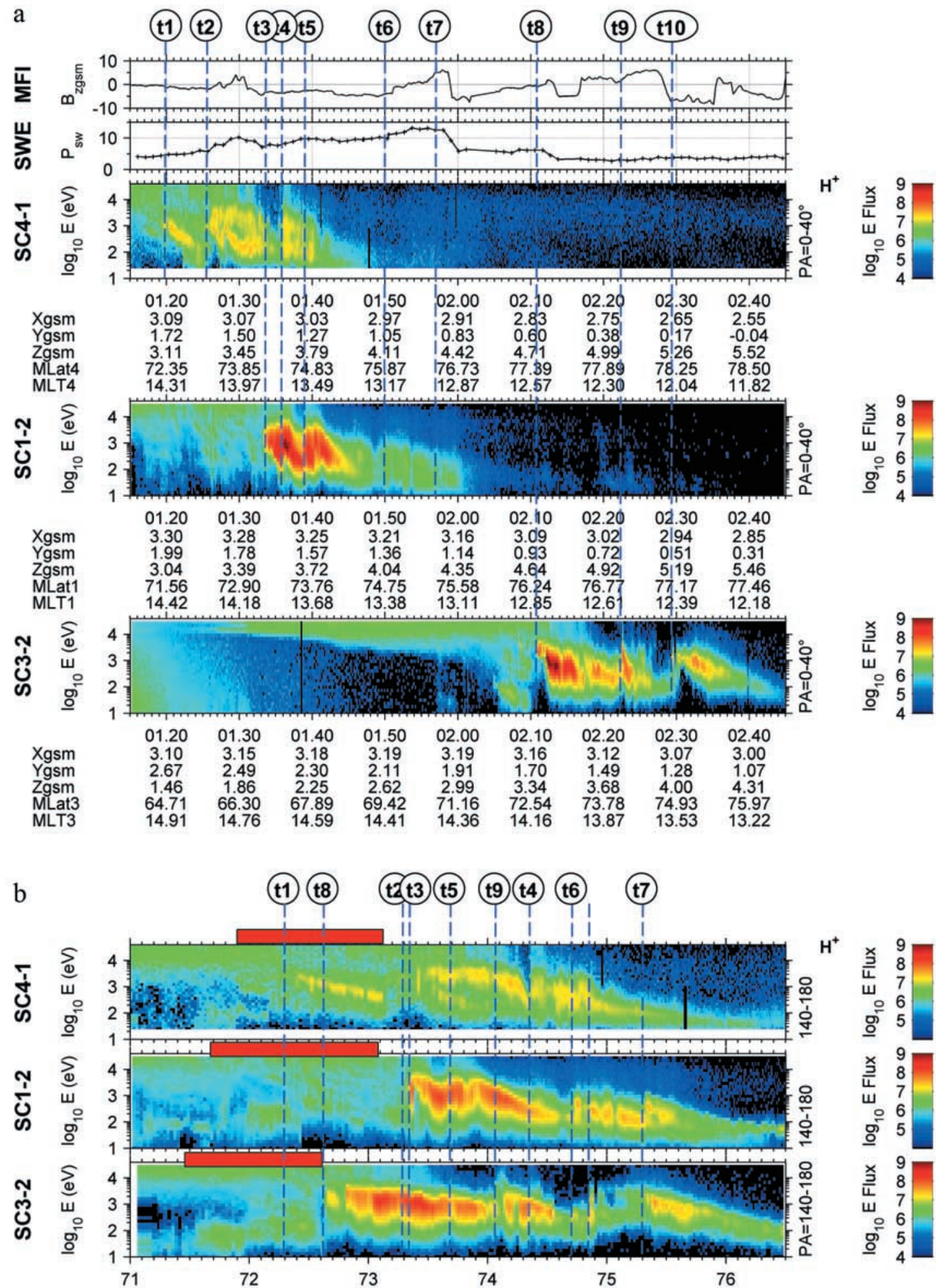

Figure 3

(labeled t1), $\sim 0125$ UT (t2), and $\sim 0135: 30$ UT (t4). The ion density (not shown) was very high $\left(>30 \mathrm{~cm}^{-3}\right)$, and thus some saturation of the CIS-1 detector was probable in that case. Nevertheless, with the information that the IMF was pointing southward, the classical energy-latitude (time) dispersion ramps are evident in the spectrogram, although the second ramp starting at 0125 UT seems to be more complex. Following the previous spacecraft by $\sim 1000 \mathrm{~km}$, 
the SC1 spacecraft (Figure 3a, middle color panel) crossed the OCB (again defined by the drop-off of energetic electrons) at $\sim 0121 \mathrm{UT}\left(71.70^{\circ}, 14.4 \mathrm{MLT}\right)$, that is, at an OCB latitude identical to that detected by SC4. Notice that SC2 (the CIS instruments are permanently switched off on this spacecraft) crossed the OCB at $\sim 0118$ UT $\left(71.59^{\circ}\right.$, $14.35 \mathrm{MLT}$ ), with approximately the same location in magnetic coordinates. A number of dispersed ion structures are evident in the SC1/CIS2 spectrogram, at $\sim 0134 \mathrm{UT}$ (t3), $\sim 0136$ UT (t4), and $\sim 0139$ UT (t5). The ion density reached extreme values, $\sim 130-140 \mathrm{~cm}^{-3}$, near the maximum of the CIS2 instrument's range. Around $~ 0150$ UT (t6) and $\sim 0157$ UT (t7) it is possible that new, although less intense, ion injections occur at energies $E_{i} \leq 1 \mathrm{keV}$, somewhat lower than those of the two previous injections. The pitch angle distribution (not shown) indicates that upward moving ions were detected by SC1 until $\sim 0201$ UT. The final spacecraft (SC3) lagged behind $\mathrm{SC} 1$ by $\sim 11,000 \mathrm{~km}$, or $30-40 \mathrm{~min}$. The spacecraft crossed the OCB at $\sim 0202$ UT $\left(71.45^{\circ}, 14.33 \mathrm{MLT}\right)$, that is, again at the same latitude. Thus, in spite of changes in the solar wind pressure and/or the IMF direction, the OCB did not move far during this 01180202 UT time interval. However, the conclusions drawn from this must be softened as the OCB boundary was never crossed by Cluster during the major pressure jump. Spacecraft SC3 first encountered a structure at time (t8), it was characterized by a first step-like structure around $2-4 \mathrm{keV}$ followed by an energy dispersion. New, sporadic injections were also present, particularly at $\sim 0222: 30$ UT (t9). The ion density of this injection was still very large, peaking at $\sim 110 \mathrm{~cm}^{-3}$ at $\sim 0213$ UT and $\sim 40 \mathrm{~cm}^{-3}$ at $\sim 0224$ UT. The last ion dispersed structure was observed by SC3 at t10 0229:30 UT $\left(74.87^{\circ}, 13.55\right.$ MLT).

[16] Summarizing this first survey of the CIS data, successive cusp crossings by three Cluster spacecraft revealed multiple dispersed ion injection structures, roughly localized around $72^{\circ}-74^{\circ}$ and $\sim 14.0$ MLT, and, if time variations are assumed, with a suggested repetition rate of $\sim 2-10$ min for the most energetic. At a rough guess, the comparison of the timing $\mathrm{t} 1, \ldots, \mathrm{t} 10$ with the solar wind dynamic pressure and the IMF $B_{z}$ profiles suggests that some of these injections are related to pressure changes (before $0210 \mathrm{UT}$ ), and others related to IMF $B_{z} / B_{y}$ orientation changes (after 0205 UT). All of these points will be discussed later.

[17] Figure $3 \mathrm{~b}$ is designed to examine whether the observed variations are really temporal, or result from the successive crossing of localized regions of permanent injections dispersed in latitude (or longitude). Figure $3 \mathrm{~b}$ presents the magnetic latitude for each spacecraft, now versus the spectrogram of upward moving ions ( $\mathrm{PA}=$ $\left.140^{\circ}-180^{\circ}\right)$. Vertical time marks t1...t10 again refer to the time when each ion structure is first detected. Above each panel is given a red horizontal bar delineated, on one side, by the OCB and, on the other side, by the equatorward electron $\left(E_{e} \sim 50-100 \mathrm{eV}\right)$ cusp boundary given by the PEACE instrument (data not plotted). This region, $1^{\circ}-1.5^{\circ}$ wide in latitude, is also characterized by trapped or counterstreaming electron beams and can be defined as the high-latitude boundary layer (entry layer), which lies partly on closed field lines. Its position, $\sim 71.5^{\circ}-72.8^{\circ}$, remained relatively stable within $\pm 0.3^{\circ}$ MLAT motions, for at least $50 \mathrm{~min}$, regardless of the IMF direction and/or the $P_{s w}$ pressure. To focus on the cusp ion injections, when the injections are ordered by latitude, their succession (in time) appears highly disordered, although one could distinguish two (or three) contiguous regions, $\sim 1^{\circ}$ wide, of preferential ion precipitation. Figure 3 reveals how difficult it is, even when data are available from a three-spacecraft fleet, to separate the time and space aspects of midaltitude cusp injection. Because of the spacecraft's poleward motion across the cusp field lines, of the order of $\sim 1^{\circ} / 10 \mathrm{~min}$, and the separation of the spacecraft $\mathrm{SC} 1$ and $\mathrm{SC} 4, \sim 1^{\circ}$ in latitude, it is very likely that fortuitous and misleading space "phasing" occurs when injections are plotted versus latitude and spacecraft. Fortunately, the IMAGE/ FUV data will decisively solve this ambiguity.

\subsection{IMAGE/FUV Data}

[18] The Far Ultra-Violet FUV/SI-12 proton aurora imager is most sensitive to high-density, $\geq 1-2 \mathrm{keV}$ protons [Gérard et al., 2001]. Thus we may anticipate that the best times for imaging are between 0130 and 0200 UT, when one (or more) Cluster spacecraft detects very intense bursts of $\geq 1-2 \mathrm{keV}$ ion injections around 14.0-14.5 MLT, $72^{\circ}-$ $74^{\circ}$ MLAT. To manage the full sequence of FUV/SI-12 images, the mean count rates in pixels of $0.5^{\circ}$ ILAT $\times$ 0.5 MLT were first determined for each image. Then, to facilitate comparison with the Cluster observations, keograms giving the MLAT-time (at a given MLT range) or MLT-time (at a given latitude MLAT range) brightness profiles were constructed. For the full interval of interest, 0115-0245 UT, Figure 4 gives a summary of the simultaneous Cluster/CIS and IMAGE/SI-12 observations, together with the IMF $B_{z}$ and $P_{s w}$ reference profiles (first two panels), which lag by the time shift specified in section 3 . Figure 4 gives the MLT-time intensity keograms (in absolute units, kR) along four adjacent $0.5^{\circ}$ latitude intervals ranging from $72.5^{\circ}$ to $74.5^{\circ}$ MLAT; the three MLAT-time keogram, for three contiguous 0.5 MLT sectors, ranging from $13.0 \mathrm{H}$ to $14.5 \mathrm{MLT}$; and portions of the

Figure 4. Simultaneous interplanetary data, IMAGE-SI-12 keograms, and Cluster CIS data for the period 0115-0245 UT. From top to bottom: IMF $B_{z}(\mathrm{nT}) ; P_{s w}(\mathrm{nPa})$; four successive MLT - time intensity keograms integrating the Ly $\alpha$ emissions along four $0.5^{\circ}$-spaced latitude bins, from $72.5^{\circ}-73.0^{\circ}$ to $74.0^{\circ}-74.5^{\circ}$ MLAT; three successive, 0.5 MLT spaced MLAT time intensity keograms from 13.0-13.5 H to 14.0-14.5 MLT; and three ion spectrograms (downward moving ions for $\mathrm{SC} 4$ and SC3, upward moving ions for SC1). Above the SC1 spectrogram is given the measured SI-12 count rate along the $\mathrm{SC} 1$ track $\left(I_{f u}\right.$, in counts/pixel, black line), the expected SI-12 count rate computed from the ion energy flux measured by $\mathrm{SC} 1 / \mathrm{CIS}$ ( $I_{\text {cis }}$, blue line), and the ion average energy $\langle E\rangle$ (in $\mathrm{keV}$, green line). Tracks of each spacecraft are indicated by colored segment lines in the appropriate keograms (SC1, black; SC2, red; SC3, green; and SC4, blue). Dashed vertical lines show the main injection times. 


\section{CLUSTER-CIS/IMAGE-FUV 14-07-2001}

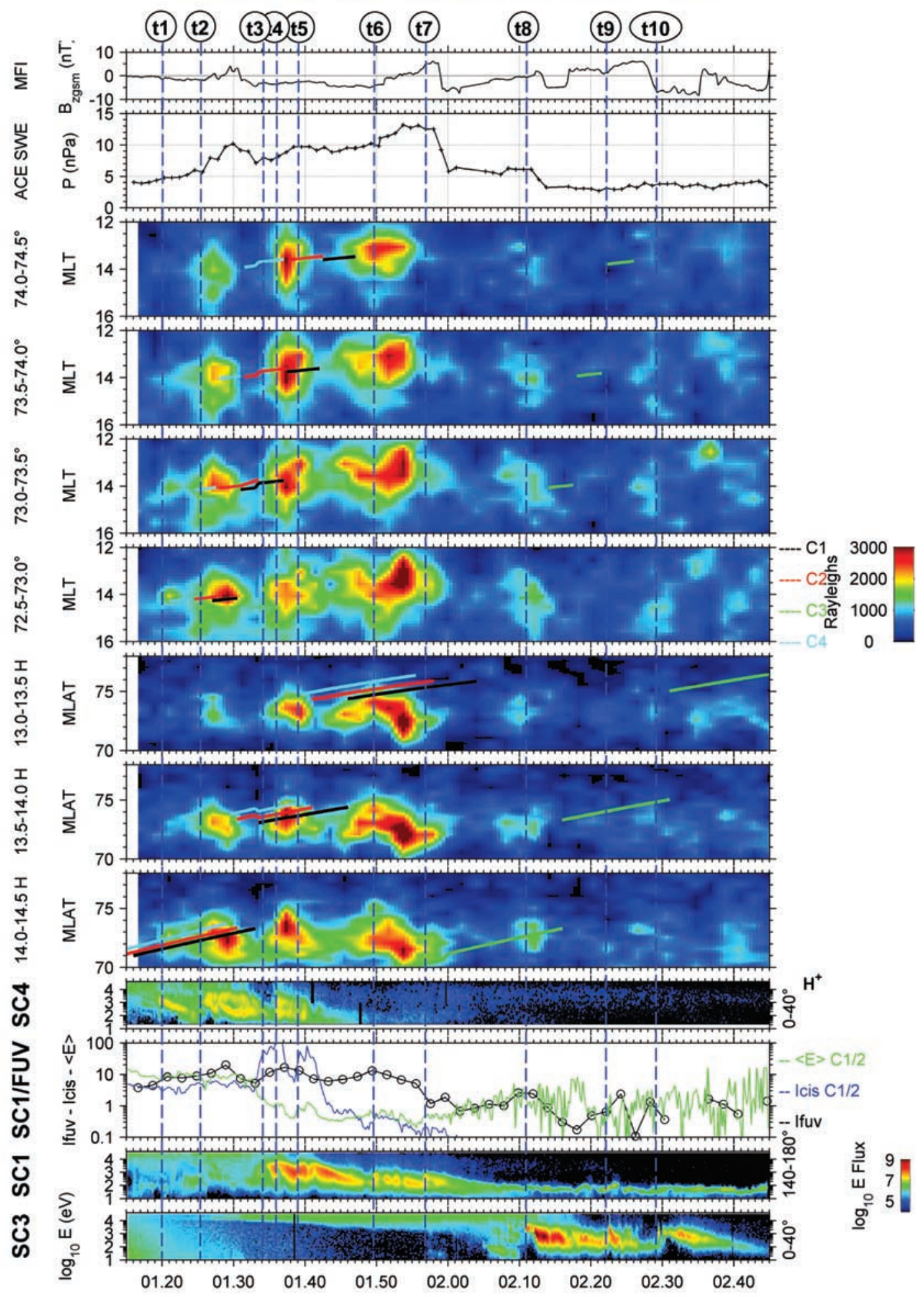

Figure 4

spectrograms already presented in Figure 3, the downward moving ion spectrograms for $\mathrm{SC} 4$ and $\mathrm{SC} 3$, and the upward moving ion spectrogram for $\mathrm{SC} 1$, associated with a plot giving intensities profiles for SC1. The predicted spacecraft paths, mapped to the ionosphere using the T01 model adjusted with $P_{s w}$ and IMF parameters, are also plotted in the appropriate keograms. To emphasize the possible association between ion injections, IMAGE spots, and IMF/ $P_{s w}$ features, vertical lines are again plotted at the reference times $\mathrm{t} 1, \ldots \mathrm{t} 10$. 
[19] It is highly evident that almost all of the ion injections detected by the Cluster/CIS instruments were associated with proton aurora brightening. The first ion ramp detected at t1 ( 0120 UT) by spacecraft SC4 was associated with the first bright spot (max $1.4 \mathrm{kR})$ observed by FUV/SI-12 in the 14.0-14.5 MLT sector (Figure 4). During that time interval the path of SC4 crossed this spot while $\mathrm{SC} 1$ was located equatorward of the Ly $\alpha$ aurora. At the time of this first injection, the IMF $B_{z}$ was slightly negative $(\sim-2 \mathrm{nT})$ and the $P_{s w}$ pressure had begun increasing from its pre-event level. The first and most intense brightening detected by FUV/SI-12 reached $3.2 \mathrm{kR}$ at $\sim 0128 \mathrm{UT}$ and extended over $\sim 1.5 \mathrm{MLT}$ and $1.5^{\circ}$ MLAT. It coincided with the $\mathrm{H}^{+}$ion injection at $\mathrm{t} 2$, which was detected by $\mathrm{SC} 4$ but not by SC1. The computed mapping of the SC1 path to ionospheric altitudes (see Figure 4, 14.0-14.5 $\mathrm{H}$ plot and $73.0-73.5^{\circ}$ plot), however, indicated that $\mathrm{SC} 1$ should have encountered the same ion structure. Problems raised by the field mapping and the spread of the spots observed by SI-12 in MLT/MLAT will be discussed in section 5.1. This particular case was related to a drastic increase of the $P_{s w}$ dynamic pressure and a detailed examination of the SC1 track demonstrates that the track could have in fact been tangent to the spot (before any averaging). An examination of the PEACE data (not shown) confirms this point; the electron precipitation detected by $\mathrm{SC} 1$ was near its background while SC2 started to detect an intense electron precipitation at $\sim 0132$ UT. Regardless, this injection was clearly related to an increase in the IMF $B_{z}$ component (following a short rotation toward $B_{z}>0$ ) and, above all, it coincided with a fairly large increase in pressure, which reached $10 \mathrm{nPa}$. The third injection, simultaneously detected by $\mathrm{SC} 4$ and $\mathrm{SC} 1$ at $\mathrm{t} 3 / \mathrm{t} 4$ ( $\sim 0135 \mathrm{UT})$, corresponded to the second most intense brightening ( $\max \sim 2.7 \mathrm{kR})$ centered at 13.5-14.0 MLT and $73^{\circ}-74^{\circ}$ MLAT; SC1 crossed near the spot's center, while $\mathrm{SC} 4$ crossed it on its less extended, poleward side. Again, the ion injection and its associated proton aurora were correlated with a southward pointing IMF $\left(B_{z} \sim-2.5 \mathrm{nT}\right)$ and an increase in dynamic pressure of up to $\sim 9.5 \mathrm{nPa}$.

[20] The most intense localized proton aurora seen by FUV/SI-12 began at $\sim 0147$ UT, and was only partially observed around t6 $(\sim 0150$ UT) by the SC1/CIS instrument. Simultaneously $P_{S w}$ increased and reached its maximum around $\sim 0153$ UT (properly shifted in time) and remained steady for about 4 min. Analysis of the spacecraft orbital tracks plotted on the keograms indicates that SC4, $\mathrm{SC} 2$, and $\mathrm{SC} 1$ were traveling poleward of the auroral form, while SC3 stayed slightly equatorward of the auroral form. If the mappings were correct, only $\mathrm{SC} 1$ should have been positioned to observe the ion precipitation. In the various spectrograms the precipitating ion flux detected by $\mathrm{SC} 1$ after $\sim 0150$ UT was very low, and only upward moving ions were detected. Therefore only the SC1 $\left(\mathrm{PA}=140^{\circ}-\right.$ $180^{\circ}$ ) spectrogram is provided here. It could be the case that the upward moving ions were detected only after being injected equatorward of the SC1 spacecraft, mirrored below the spacecraft, and convected poleward. This logical scenario, which relies on there being at least a poleward convection component, will be discussed in section 5.3. To return to the polar aurora identified in the keograms, its apparent latitudinal and westward motion appears to be related to changes in $P_{s w}$ and $B_{z}$ and/or $B_{y}$.

[21] The $P_{s w}$ dynamic pressure decreased dramatically at 0200 UT, but remained relatively high up to 0213 UT. In the meantime, the IMF orientation changed from northward to southward, and IMF $B_{y}$ increased to $\sim+13 \mathrm{nT}$. After 0200 UT SC1 and SC 4 were both moving above the polar cap, as evidenced by SCl's detection of upward flowing low-energy $(<100 \mathrm{eV})$ ionospheric ions (see SC1 spectrogram at pitch angle $=140^{\circ}-180^{\circ}$ ), while $\mathrm{SC} 3$ still was positioned on dayside field lines connected to the plasma sheet. However, we may envisage some $2-3 \mathrm{~min}$ error in the time lag, as SC1 detected at $\mathrm{t} 7 \sim 0157$ UT the upward moving part of a clear injection. The CIS instrument on the trailing spacecraft, $\mathrm{SC} 3$, detected its first ion injections at $\mathrm{t} 8$, followed by two others at $\mathrm{t} 9$ and $\mathrm{t} 10$. Fortunately, the first injection detected by SC3, at $\mathrm{t} 8 \sim 0210 \mathrm{UT}$, was sufficiently intense to be precisely correlated with the next brightening ( $\max \sim 1.5 \mathrm{kR}$ ) detected by SI-12 (see Figure 4, 14.0$14.5 \mathrm{H}$ plot and $72.5-73.0^{\circ} \mathrm{plot}$ ). The interplanetary parameters showed, again within an error of $2-3 \mathrm{~min}$ in the time lag, a simultaneous small increase in the pressure and a slight southward turn in IMF $\left(B_{z} \sim-1 \mathrm{nT}\right)$. Later, successive ion ramps are apparent between 0210 and 0216 UT in the SC3 spectrogram. The next energy-dispersed structure observed at $\mathrm{t} 9$ did not produce any discernible FUV signal and, at a first glance, was not associated with any change in interplanetary parameters. Finally, the latest ion injection detected by Cluster occurred at t10 0229 UT, and had a $P_{s w}$ pressure that recovered to $\sim 3 \mathrm{nPa}$. The observed ion energy dispersion was typical of an IMF $B_{z}<0$ orientation; this orientation changed dramatically at 0229 UT. Our analysis of Ly $\alpha$ emissions did not reveal a significant count rate, even though a spot appeared later, at $\sim 0235 \mathrm{UT}$, at $73^{\circ}$ MLAT and $\sim 12.5$ MLT (not shown).

\section{Discussion}

[22] On 14 July 2001, over a period of about $90 \mathrm{~min}$, the Cluster spacecraft fleet crossed the northern midaltitude cusp in the postnoon sector; the crossing occurred under high solar wind dynamic pressure $(5-13 \mathrm{nPa})$ and rather steady interplanetary magnetic field conditions (IMF $B_{y}>0$, $\left.B_{z}<0\right)$. Meanwhile, the IMAGE/FUV/SI-12 instrument was continuously collecting Doppler-shifted Ly a proton aurora global images. The main results can be summarized as follows.

[23] CIS instruments detected sporadic, very intense, energy-dispersed $\mathrm{H}^{+}$ion injections, at times overlapping. Having the instruments on multiple spacecraft made it possible to discern time-pulsating injection, with a quasiperiodic repetition time of about 8-10 min; these injections were localized in a relatively narrow region around $72^{\circ}-74^{\circ}$ ILAT in the 14.0 MLT postnoon sector.

[24] Observed pitch angle distributions and delays between arrival times of downward moving and subsequent upward moving ions, favor dispersion in time, rather than space.

[25] Simultaneously collected proton aurora images reveal a sequence of transient and very intense $(\geq 3 \mathrm{kR})$ Ly $\alpha$ brightenings concentrated in the postnoon sector 
13.0-14.5 MLT and $72^{\circ}-74^{\circ}$ MLAT, a region that was fortunately crossed by Cluster during the same time period.

[26] In the first part of the event when the ram pressure was higher than $\sim 5 \mathrm{nPa}$, a striking one-to-one correlation occurred between injections and their proton aurora counterparts on the one hand, and the sharper increases in the interplanetary solar wind dynamic pressure on the other hand. Nevertheless, in the second part of the event when the pressure was lower, cusp transients apparently corresponded to changes in the IMF.

[27] This section will continue in four stages. First, we make quantitative comparisons between the expected SI-12 signal deduced from ion energy fluxes measured by Cluster/ CIS at $\sim 5 R_{E}$ altitude, and the brightness actually measured in the ionosphere by FUV/SI-12. Second, we use UV images to extract additional information regarding the intensity, size, and movements of the observed spots, and examine their possible relationship to large-scale changes in the dynamic pressure and/or the IMF orientation. After that we will take advantage of the quasi-simultaneous detection of an ion stepping injection by three spacecraft to carry out one analysis of its electrodynamical structure, convection, field-aligned currents, and electron precipitation. This analysis will strengthen the interpretation in terms of moving FTEs. Finally, after inferring the location of the probable reconnection site, we will discuss evidence indicating that solar wind pressure in the solar wind/magnetosheath may trigger transient reconnection and, afterward, couple the dusk magnetopause to the dayside ionosphere through FTEs.

\subsection{Comparison Between FUV Brightness and CIS Energy Flux}

[28] In this part we quantitatively compare the ion $\left(\mathrm{H}^{+}\right)$ fluxes measured by the CIS instruments and the resulting brightness measured remotely by SI-12 at ionospheric altitudes along the satellite footprint. Making such comparisons is not straightforward, as modeling and calibrations (see Frey et al. [2003b] for a review) revealed that the total SI-12 signal was not simply proportional to the proton energy flux. Previous quantitative comparisons in the nightside auroral zone showed that theoretical and observed SI-12 count rates were consistent, and differed by a factor of two or less [Frey et al., 2003c]. Except for the qualitative evaluation presented by Phan et al. [2003], quantitative comparisons of measurements taken within the cusp have, to our knowledge, never been made as collecting data for this region involves two crucial difficulties: (a) the in situ ion precipitation is more localized, and comparisons are highly dependent on the accuracy of the mapping model and the spread of the initial confined beam, (b) the ions precipitate with energies of the order of $1-2 \mathrm{keV}$ or less, which makes any evaluation of the count rate highly dependent on the initial energy.

[29] Figure 4 depicts this comparison for the SC1 Cluster spacecraft. Three profiles are plotted: the $I_{f u v}$ intensity profile along the track of the spacecraft (counts, black line/circles), the expected SI-12 count rate $I_{\text {cis }}$ (blue profile), and the average ion energy $\langle E\rangle$ (green, in keV). The SI-12 brightness profile $I_{f u v}$ is extracted from the images taken every two minutes and, as already mentioned, averaged over a rather wide region, $0.5^{\circ}$ MLAT by 0.5 MLT, containing the computed footprint of the magnetic field line passing through the instantaneous spacecraft position. The energy flux in the loss cone at Cluster's altitude $\left(\sim 5^{\circ}\right)$, after conversion into the ionosphere, was used to compute the total expected count rate/pixel, $I_{c i s}$, through the energydependent overall transfer function [Frey et al., 2003b]. CIS data are smoothed over $12 \mathrm{~s}$ or $16 \mathrm{~s}$, that is, over $60 \mathrm{~km}$ at Cluster altitude, or $\sim 6-10 \mathrm{~km}$ along the Cluster's ionospheric track. This space resolution is still quite higher than the FUV/SI-12 resolution $(\sim 50 \mathrm{~km})$ and could account in part for the observed uncertainties.

[30] Up to t3 ( 0134 UT) CIS detected only plasma sheet protons having an average energy of $\sim 7-15 \mathrm{keV}$. The expected (blue) and measured (black) Ly $\alpha$ count rates are $\sim 3-7 /$ pixel and 4-10/pixel, respectively, that is, with an observed/calculated ratio of $\sim 2$, as already noted by Coumans et al. [2002] for the duskside oval. However, some intensification ( $\sim 20$ counts) in $I_{f u v}$ is evident around $0129 \mathrm{UT}$, and this fact immediately raises the primary concern regarding this comparison: how precise is the mapping? Even when the SI-12 brightness is extracted from a rather coarse "image," it is clear that the SC1-mapped path intercepts the first intense spot centered on 0129 UT, while the low-energy $(\leq 5 \mathrm{keV})$ ion flux measured by Cluster at $\sim 5 R_{E}$ altitude is near that of its background (see Figure 4, 14.0-14.5 H plot). A number of magnetic models have been tested to improve the comparison. In a comparison of cusp Cluster observations at $\sim 7.5 R_{E}$ altitude and of the associated FUV-SI12 spot, Phan et al. [2003] used the T-01 model field for mapping [Tsyganenko, 2002]. They showed that a greatly improved agreement was found when the input solar wind pressure was assumed to be twice the measured pressure, $33 \mathrm{nPa}$ instead of $15 \mathrm{nPa}$. Though the agreement achieved for this first event is somewhat disappointing, the best agreement for our overall pass was obtained with the T01 model, with $\mathrm{IMF}=(-8,+5,-5) \mathrm{nT}$, and $P_{s w}=10 \mathrm{nPa}$ before $0133 \mathrm{UT}, P_{s w}=25 \mathrm{nPa}$ within the 0133-0200 UT interval, and $P_{s w}=6 \mathrm{nPa}$ after $0200 \mathrm{UT}$. Note that a slight offset, either in latitude $\left(-0.5^{\circ}\right)$ or MLT $(+0.5 \mathrm{H})$ greatly diminished the SI-12 intensity around 0125-0130 UT; this offset could be a result of the abrupt changes in $P_{s w}$ (and to a lesser extent, in the IMF). Nevertheless, an error of $0.5^{\circ}$ is within the expected uncertainties for mapping over distances of 4-6 $R_{E}$.

[31] The two incoming proton injections observed by Cluster/SC1 between $\sim 0133$ and 0143 UT are characterized by two energy flux bursts centered on $\sim 0136$ and 0140 UT. The expected $I_{\text {cis }}$ intensity peaks at $\sim 150$ and $\sim 80$ counts/pixel, respectively, while the average energy is less than $2 \mathrm{keV}$. Owing to its poor time resolution $(\sim 2 \mathrm{~min})$, the FUV/SI-12 instrument cannot really discriminate between the two (or more) injections and, unfortunately, does not detect the peaks. Nevertheless, except for the SI-12 intensity at $\sim 0135 \mathrm{UT}$, the expected and measured intensities within this time interval agree within a factor of 2. Later, around 0150 UT, the SI-12 brightness along the SC1 track reaches $\sim 13$ counts/pixel, whereas the expected $I_{\text {cis }}$ intensity is negligible. In this case, although a rather high solar wind pressure is applied $(25 \mathrm{nPa})$, we again suspect a small offset in MLAT/MLT and/or a spreading of the Ly $\alpha$ spot. As reported by Gérard et al [2001], these discrepancies are likely due to the $\mathrm{H}^{+}$beam $-\mathrm{H}$ atom 

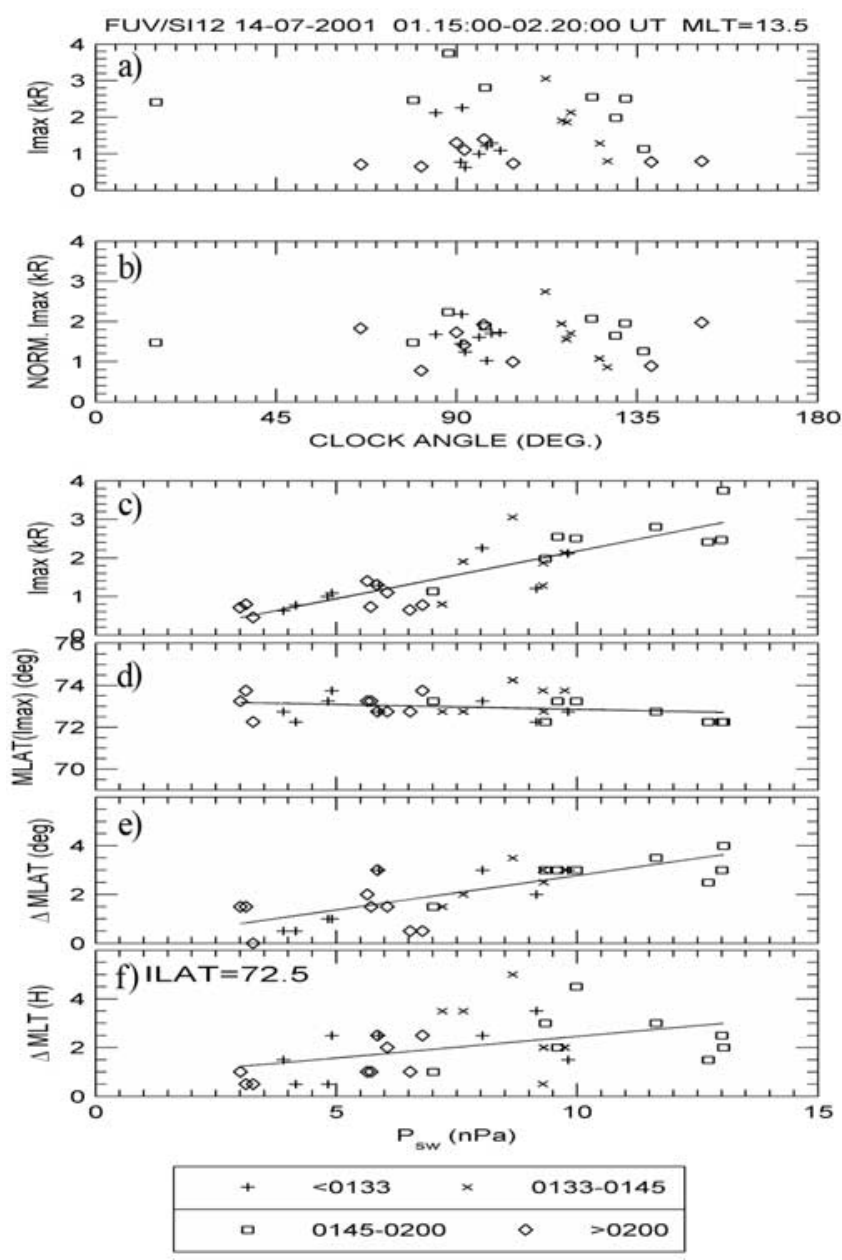

Figure 5. Dependence of Ly $\alpha$ emission properties with the IMF clock angle $\theta_{I M F}$ for the 0115-0220 UT time period and the 13.5-14.0 MLT sector: (a) peak Ly $\alpha$ intensity $I_{\max }(\mathrm{kR})$ and (b) linearly normalized peak Ly $\alpha$ emission, $I_{\max } \times\left(\left\langle P_{s w}\right\rangle / P_{s w}\right)$, where $\left\langle P_{s w}\right\rangle$ is the averaged solar wind dynamic pressure over the full time interval of interest. Also shown is the dependence of Ly $\alpha$ emission properties with the solar wind dynamic pressure $P_{s w}(\mathrm{nPa})$ : (c) peak Ly $\alpha$ intensity $I_{\max }(\mathrm{kR})$; (d) magnetic latitude in degrees of the brightest pixel, $M L A T\left(I_{\max }\right)$; and (e) latitudinal extent (in degrees) of the Ly $\alpha$ spot, $\triangle M L A T$, and (f) its azimuthal extent, $\triangle M L T$ (in hours), defined by the contour at $I_{\max } / 4$. Experimental points have been distinguished by four time intervals.

charge exchange process acting between 150 and $\sim 700 \mathrm{~km}$ altitude, resulting in a spreading of the UV proton aurora. Therefore, in spite of the difficulties encountered, we have demonstrated that the absolute Ly $\alpha$ brightness measured by SI-12 is definitively related to incoming ion fluxes. This quantitative result is promising and will encourage future conjugate studies of the cusp.

\subsection{Morphology of the Proton Aurora: IMF and/or Pressure Control}

[32] Our analysis is motivated by the recent results of Lockwood et al. [2003] that interpreted a strong relationship between the intensity of cusp proton emissions and the $\theta_{\mathrm{IMF}}$ clock angle as an indirect evidence of component reconnection. For the 13.5-14.0 MLT sector Figure 5 shows scatterplots of various quantities as a function of two lagged interplanetary parameters, the IMF clock angle $\theta_{\mathrm{IMF}}$ (Figures $5 \mathrm{a}-5 \mathrm{~b}$ ), and the solar wind dynamic pressure $P_{s w}$ (Figures $5 \mathrm{c}-5 \mathrm{f}$ ). We examine first the variations in the peak Ly $\alpha$ intensity, $I_{\max }$, with the IMF clock angle, $\theta_{\mathrm{IMF}}$. Figure 5a shows $I_{\max }$, while Figure $5 \mathrm{~b}$ shows the normalized $I_{\max }$ intensity that is linearly corrected for variations of the solar wind pressure. From Figures $5 \mathrm{a}-5 \mathrm{~b}$ it can be concluded that the peak proton emission displays a large scatter, but does not show any dependence on $\theta_{\text {IMF }}$ between $60^{\circ}$ and $150^{\circ}$, even after density normalization. This result contrasts with the clock angle dependence observed by Lockwood et al. [2003] after a southward turning of the IMF. The peak intensity varied greatly, from $\sim 0.5 \mathrm{kR}$ to $3.5 \mathrm{kR}$, for a $\sim 60^{\circ}$ to $160^{\circ}$ clock angle rotation. Lockwood et al. [2003] simulated the ion population resulting from component merging at general clock angles and locations and subsequently estimated the resulting Ly $\alpha$ emissions. In the case of component merging at a fixed reconnection site, the resulting bulk flow of the accelerated ions through the magnetopause is highly dependent on the sheath clock angle $\theta_{s h}$, with larger $\theta_{s h}$ (specifically when $\theta_{s h}$ approaches $\pi$ ) corresponding to increased acceleration at the magnetopause. The SI-12 instrument response is crucial for explaining the observed $\mathrm{I}_{\max }-\theta_{\mathrm{IMF}}$ variations. In effect, higher precipitating ion velocities generate more intense Ly $\alpha$ emissions, and the resulting simulations were in agreement with $I_{\max }$ normalized $\theta_{\mathrm{IMF}}$ observations (assuming $\theta_{\mathrm{IMF}} \sim$ $\theta_{\text {sh }}$ ). For 14 July 2001, our SI-12 observations definitively did not include such a modulation with the IMF clock angle. This finding could indicate that antiparallel merging is probable, in a site far from the subsolar region.

[33] Next, we analyze the pressure dependence of the peak intensity $I_{\max }$ (Figure $5 \mathrm{c}$ ), the latitude position of maximum intensity, the latitudinal and magnetic local time (Figure 5f) extents of the SI-12 proton emission spot. The maximum Ly $\alpha$ intensity $I_{\max }$ is proportional to the dynamic pressure, according to the least squares fitted relation: $I_{\max }(\mathrm{kR})=0.246 P_{s w}(\mathrm{nPa})-0.287$. In spite of the limited data set, this brightness-pressure relationship confirms the correlation seen in the most recent FUV studies [Frey et al., 2003c]. One effect, already mentioned by Frey et al., is the observed decrease in the brightness when pressure remains steady, as at the end of the third interval (after 0152 UT). At the boundary of the region, simultaneous Cluster observations (see Figure 3a, plot for SC1) show that a majority of ions were injected at low energies $(<1 \mathrm{keV})$, resulting in an attenuated SI-12 count rate. A weak dependence of the latitude location of maximum intensity on the pressure is evidenced by the fit: $\operatorname{MLAT}\left(I_{\max }\right)=73.32^{\circ}-0.042 P_{s w}(\mathrm{nPa})$. This trend was not reflected by the Frey et al. [2003c] data, probably obscured by simultaneously occurring IMF $B_{z}$ effects. Finally, our spot areas can be evaluated from Figures $5 \mathrm{e}$ and $5 \mathrm{f}, \sim 1.24{ }^{\circ}$ hours at $P_{s w}=2 \mathrm{nPa}$, and $\sim 4.14{ }^{\circ}$ hours at $P_{s w}=6 \mathrm{nPa}$, that is, identical to the estimation of Newell and Meng [1994], but more reduced than indicated by the Polar/UV images [Milan et al., 2000]. 


\section{CLUSTER-CIS-FGM-PEACE DAY=14-07-2001}

(a)
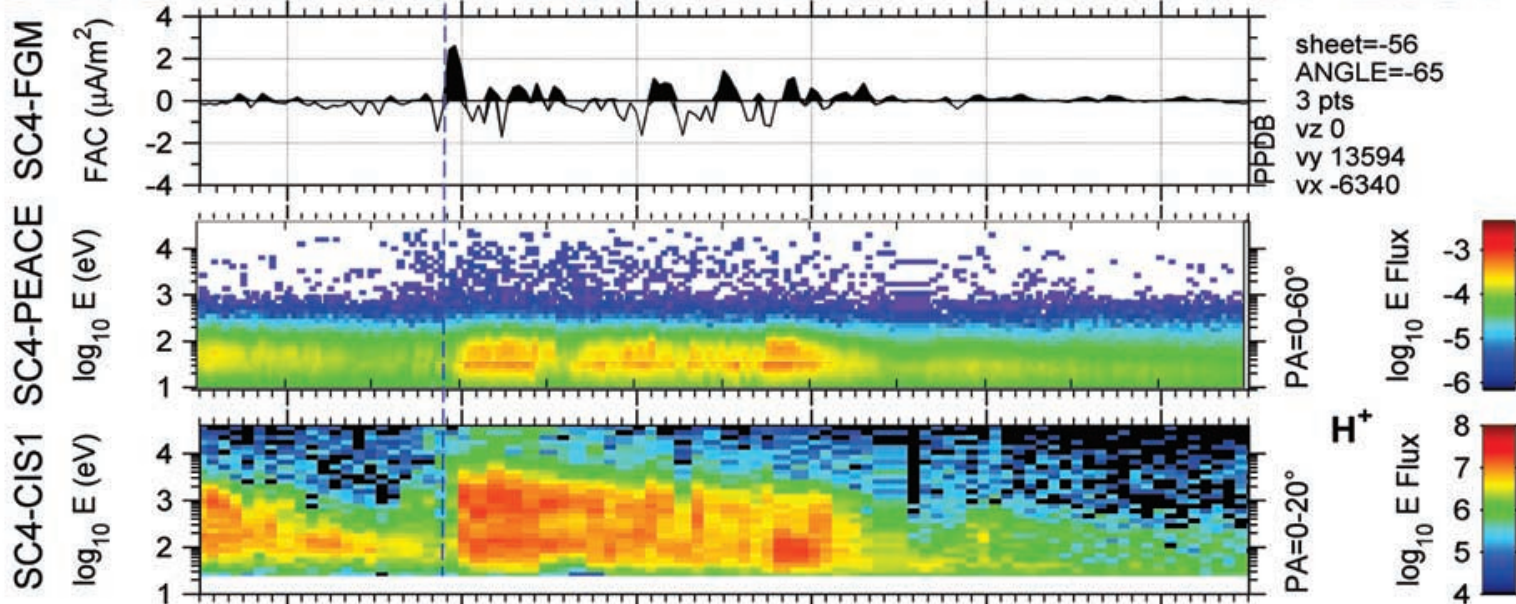

(d)

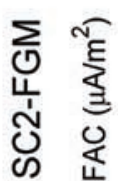
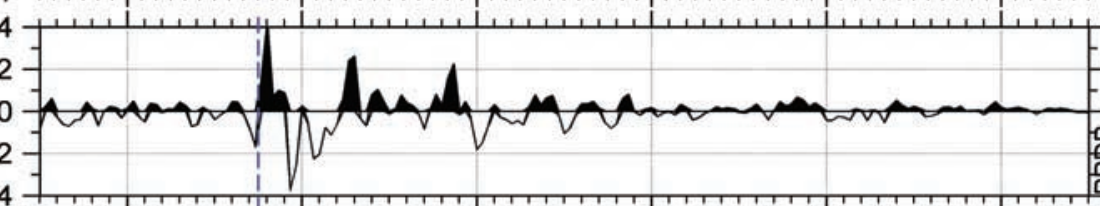

sheet $=-56$

ANGLE $=-65$

$3 \mathrm{pts}$

vz 0

vy 13594

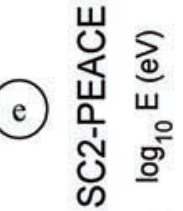

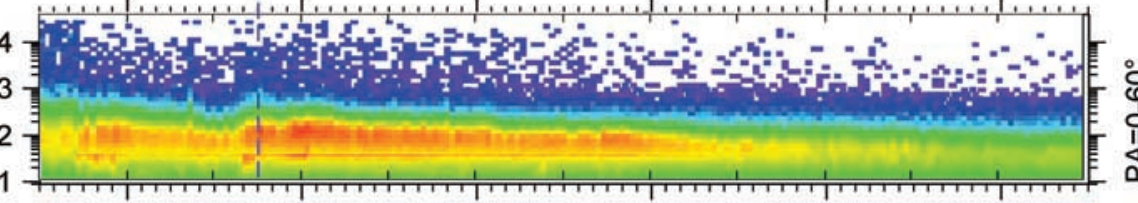

vx -6340

(1)

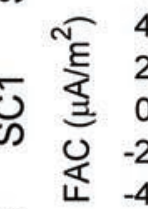
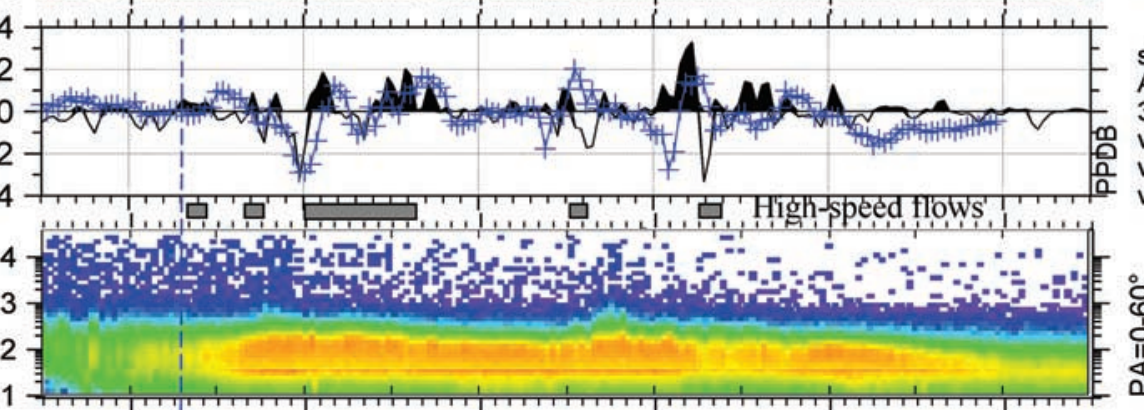

ய

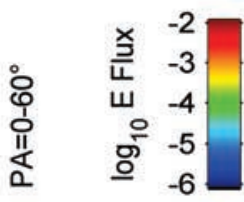

(g)

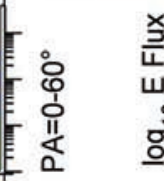

$\begin{array}{ll}\stackrel{x}{ㄴ} & -3 \\ \text { ํ․ } & -4 \\ \text { 우 } & -5 \\ \text { 으 } & -6\end{array}$

(h)

กิ ฮ

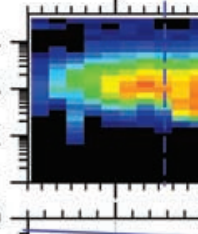

过
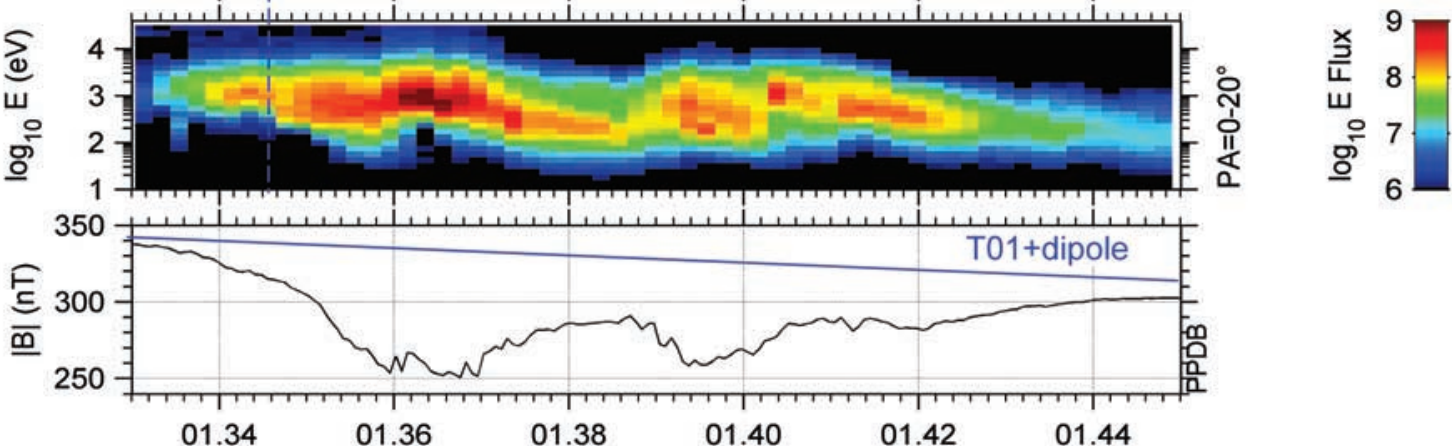

(i)

01.34

01.36

01.38

01.42

01.44

Figure 6

\subsection{Multispacecraft Analysis of an Ion Injection} Event: Evidences for Pulsed Reconnection

[34] Multipoint measurements are decisive to evaluate the motion of an event and quantify its direction and velocity. These parameters are known to be critical for distinguishing between signatures predicted by merging models and sig- natures resulting from pressure pulse models [see Sanny et al., 1996, and references therein]. Adequate interspacecraft separation between SC4, SC2, and SC1, $1200 \mathrm{~km}$ in distance or the equivalent $\sim 2-3$ min in time, offers the unique opportunity to study the evolution of small or shortlived cusp structures, like FTEs. For the selected period, 
0133-0145 UT, Figure 6 displays data from three Cluster spacecraft, SC4, SC2, and SC1. For each spacecraft, three panels show the electron spectrogram provided by the PEACE instruments, the ion spectrogram from CIS onboard SC4 and SC1, and the field-aligned current (FAC) density derived from the perpendicular magnetic field perturbation $\delta B_{\perp}$ measured by the FGM instrument. In order to compute the FAC densities we considered a current sheet moving at $V_{P}$ defined by $\vec{V}_{s / c}-\vec{V}_{P}<0$, that is, a negative s/c velocity in the current rest frame; at least up to $0138 \mathrm{UT}$, this assumption is clearly validated by a comparison with the total FAC density carried by particles (electrons + ions) (SC1, Figure 6f, blue crosses). The local magnetic field strength measured by $\mathrm{SC} 1 / \mathrm{FGM}$ is given in Figure 6i. Compared to the field given by the T01 model, this SC1 magnetic field is clearly marked by a large $\Delta B$ depression associated with the diamagnetic effect of the very dense polar cusp plasma. In this depression, identified by Polar [Zhou et al., 1997], the plasma (electrons + ions) thermal energy and diamagnetic pressure are observed to be in quantitative balance.

[35] Focusing on the energy-time ion spectrogram (Figure 6h), we first note that ions detected by SC1 form sawtooth structures made up of a sequence of decreasing ramps, followed by abrupt upward steps, for example, around 0134 UT, 0134:30 UT, 0136 UT, 0139 UT, 0140:20 UT, and having a very short repetition period, 1-3 min. Such sequences were previously reported [Lockwood et al., 1998, 2001c]; modeling [Lockwood et al., 1998] indicates they result from frequent reconnection pulses and furthermore that they are the typical signature expected at midaltitudes, where the spacecraft velocity, $V_{s / c}$ $\sim 4-5 \mathrm{~km} / \mathrm{s}$, is lower than the local convection velocity, $V_{C} \sim V_{P} \sim 10-30 \mathrm{~km} / \mathrm{s}$ (see later on in this section). A number of field-aligned current sheets (Figure 6f) are associated, with of upward FAC sheets coincident with the ion steps. Lockwood et al. [2001c] showed this configuration reveals the superposition of numerous fieldaligned currents associated with patches of reconnection, or successive flux transfer events (FTEs).

[36] To increase the chances to detect such a moving FTE tube by the three spacecraft, we concentrate on the first ion injection detected around 0134:30 UT by SC1. Although a less intense ion injection preceded at $\sim 0133: 50 \mathrm{UT}$, this ion injection is chosen as it coincided with the beginning of the simultaneous electron injection seen by the SC1/PEACE instrument (Figure 6g). Thus we associate the first major upward sheet detected by SC1 at $~ 0134: 30 \mathrm{UT}$, to the first sheet detected by SC2 at $\sim 0135: 35$ UT (Figure 6d), and finally to the first current sheet (Figure 6a), ion step (Figure 6c), and electron increase (Figure 6b) detected by SC4 at $\sim 0135: 50$ UT. These time delays can be used to evaluate the probable motion of the flux tube. We apply a three-spacecraft method [Dunlop and Woodward, 1998] to infer the motion of the flux tube at the Cluster altitude ( $\sim 5 R_{E}$ ), assuming a planar surface moving with a constant velocity perpendicular to the local, very tilted magnetic field. Using the above timings and the corresponding spacecraft locations, we obtain an estimate of a phase velocity of $V_{P} \sim[+7,-11,+2] \mathrm{km} / \mathrm{s}$ in GSM coordinates, which is primarily dawnward directed. At that point we are aware that this three-spacecraft association could be questioned. If we shift the first SC1 detection to 0134:50 UT the phase velocity is larger, $V_{P} \sim[+9,-16,+4] \mathrm{km} / \mathrm{s}$, but always dawnward directed and of the order of $15-20 \mathrm{~km} / \mathrm{s}$. Later on, other associations defined by positive FAC sheets can be proposed, for instance at 0136:14 (SC1), 0136:34 (SC2), and 0138:13 UT (SC4) that gives $V_{P} \sim[-12,-1$, $+14] \mathrm{km} / \mathrm{s}$, or 0139:00 UT (SC4), giving $V_{P} \sim[-6,+2$, $+4] \mathrm{km} / \mathrm{s}$. In that case the phase velocity, $\sim 6-12 \mathrm{~km} / \mathrm{s}$, is primarily in the poleward direction.

[37] For the 0135-0136 UT interval, Figure 7 (top) shows hodograms of the $\delta B_{\perp}$ perturbation observed by $\mathrm{SC} 1, \mathrm{SC} 2$, and SC4, plotted in the $[X-Y]_{\mathrm{GSM}}$ plane. The direction of polarization is clearly linear and indicates a dawnwardsunward direction for the FAC sheets which remain more or less unchanged from one spacecraft to the next one. Our estimates indicate a strong dawnward (westward) motion of the flux tube and a non-negligible poleward component. This orientation and motion can be related with the idealized schematic Flux Transfer Event (FTE) predicted for IMF $B_{y}>0$ (see inset, extracted from Lockwood et al. [2001c]). The elongated FTE tube is associated with two sheets of upward/downward FACs on its poleward/equatorward sides. Figure 7 (bottom) completes the survey of Cluster data for this time period. The averaged $V_{\perp}(\mathrm{cis})$ convection velocity vectors, measured in the $X$ - $Y$ GSM plane at the Cluster altitude, are plotted along the SC1 orbit path to the ionosphere from 0135 to $0245 \mathrm{UT}$; they are superposed on the SI-12 image taken at 0137:06 UT. From $\sim 0134$ to $\sim 0140$ UT SC1 entered a westward directed flow channel where the observed convection was extremely high, up to $\sim 50 \mathrm{~km} / \mathrm{s}$ at the Cluster altitude. As IMF $B_{y} \sim+7 \mathrm{nT} \gg 0$, this convection pattern and the tube motion are undoubtedly controlled by this very strong and positive IMF $B_{y}$ component. Close examination of the convection at the best available time resolution $(4 \mathrm{~s}$, not shown) indicates that three, very localized, and even faster spiky westward flows were detected at $\sim 0137 \mathrm{UT}$, 0139:15 UT and 0140:20 UT, with speeds $\geq 90 \mathrm{~km} / \mathrm{s}$. Comparison with independent EFW data (not shown) fully confirms both the timing and amplitude. This result indicates that the westward jets were detected when the

Figure 6. CIS, PEACE, and FGM data from spacecraft $(a-c)$ SC4, (d-e) SC2, and (f-i) SC1 for the time period $0133-$ 0145 UT. Except for SC2 (CIS was switched off), Figure 6 shows for each spacecraft the field-aligned current $\left(\mathrm{FAC}\right.$, in $\mu \mathrm{A} / \mathrm{m}^{2}$ ) derived from the perpendicular magnetic field perturbation $\delta B_{\perp}$ measured by the FGM instrument (upward directed FACs away from the ionosphere are positive); a color-coded, energy-time electron spectrogram from PEACE, giving the differential flux for $0^{\circ}-60^{\circ}$ pitch angle (in units of $\operatorname{ergs}\left(\mathrm{cm}^{2}\right.$.str.s.eV) ${ }^{-1}$, scales specific to each spacecraft); and a color-coded, energytime ion spectrogram from CIS, giving the differential flux for pitch angles $\leq 20^{\circ}$ in units of $\mathrm{keV}\left(\mathrm{cm}^{2} \mathrm{~s} \mathrm{keV}\right)^{-1}$. Figure $6 \mathrm{i}$ gives the local magnetic field strength measured by SC1/FGM (black line) and the magnetic field magnitude predicted along the SC1 trajectory by the T01 magnetic field model (blue line). In addition, for SC1, the FAC density carried by particles (electrons plus ions) is also plotted for comparison (blue crosses in Figure 6f). 

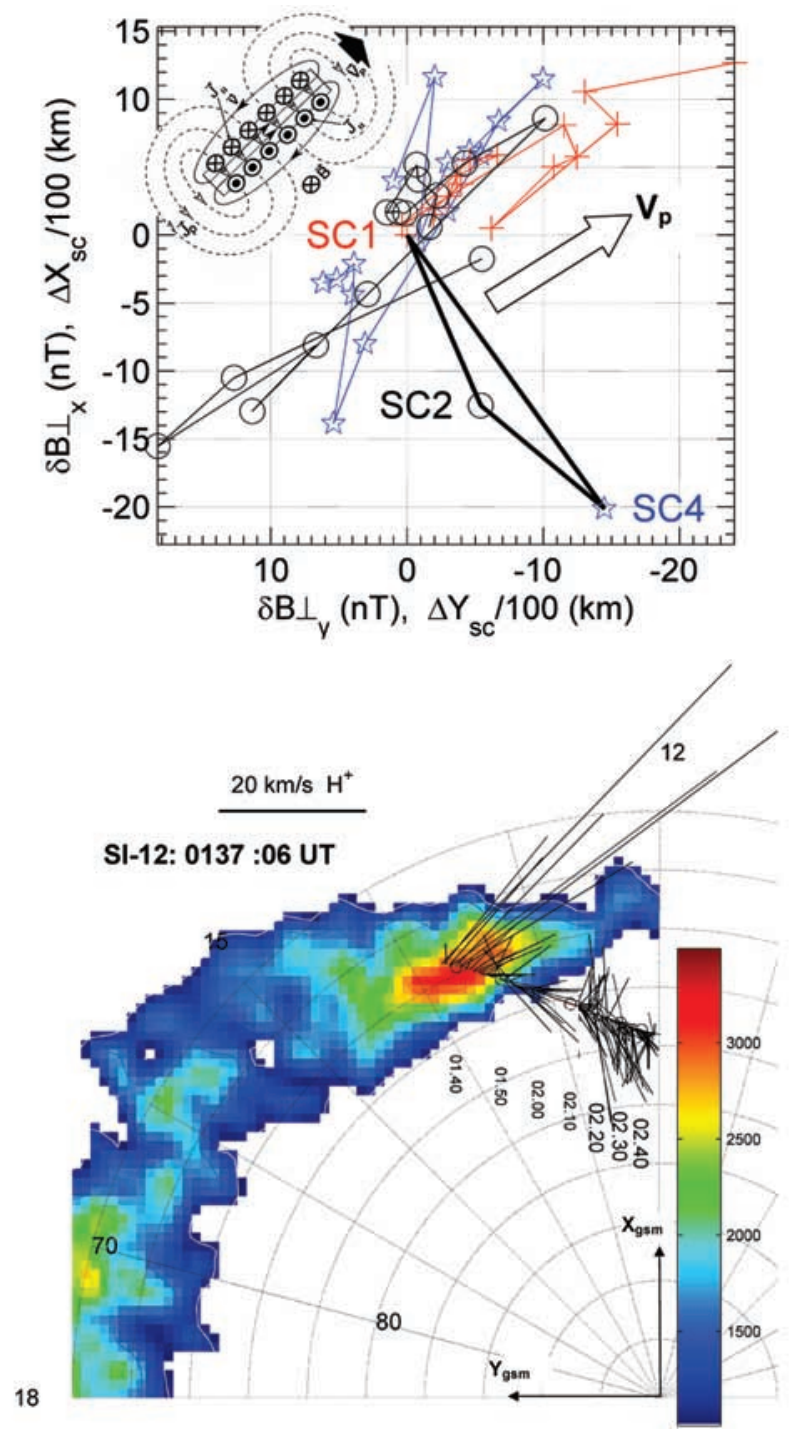

Figure 7. (top) Hodograms of the $\delta B_{\perp}$ perturbation (in $\mathrm{nT}$ ) observed between 0135 and 0136 UT by SC1, SC2, and $\mathrm{SC} 4$, mapped to the $X-Y$ GSM plane, and relative position of the three spacecraft at 0134:35 (SC1), 0135:35 (SC2), and 0135:50 UT (SC4), also in the $X-Y$ GSM plane (SC1 is taken as the reference). The direction of the estimated $V_{p}$ phase velocity is also indicated (large arrow). The inset gives the plasma flows $\vec{v}$, Pedersen currents $\vec{J}_{P}$, and field-aligned currents $\vec{J}_{\|}$(positive being upward) of an idealized elongated FTE tube moving westward (to the right) at velocity $\vec{V}_{P}$, under the action of the tension force [from Lockwood et al. [2001c]. (bottom) Convection velocity vectors (in $\mathrm{km} / \mathrm{s}$ ) at the Cluster/ $\mathrm{SCl}$ orbit corrected for the $V_{s / c}$ velocity along the orbit $(\sim 4-5 \mathrm{~km} / \mathrm{s})$ and averaged over $36 \mathrm{~s}$. Vectors (in $X-Y$ GSM coordinates) are plotted in a MLT-MLAT diagram, from 0135 to 0250 UT along the SC1 orbit track mapped to the ionosphere on the SI-12 image taken at 0137:06 UT (color coded in rayleighs). Noon (or $+X_{G S M}$ ) is toward the top, and 18 MLT (or $+Y_{G S M}$ ) is toward the left.

core of adjacent newly reconnected FTE tubes were moving over the SC1 spacecraft; the first is being studied here, and the other were appended to the first and were clearly seen throughout the FAC sheets on their poleward side and the ion step. After 0150 UT Figure 7 indicates that the convection over the polar cap is generally poleward directed, and the overall flow direction is fully consistent with the southward/duskward orientation of the IMF $\left(B_{y} \sim+8 \mathrm{nT}, B_{z} \sim-2 \mathrm{nT}\right)$. A standard twin cell pattern is substantiated by ionospheric flows measured by the SuperDARN radars [Marchaudon, 2003]. It is notable that the initially westward flux tube motion is roughly in the same direction as the central convection plotted in Figure 7 (bottom), and therefore is fully consistent with the predicted pattern of FTEs. However, at least for this injection, the tube phase velocity is lower than the averaged central flow ( $V_{\perp y} \sim-22 \mathrm{~km} / \mathrm{s}$ at Cluster), and this result contrasts with the ground-based coherent radar observations showing the "phase" or flux tube velocity to be one to two times the central convection flow [Provan et al., 1998; McWilliams et al., 2001].

[38] Even though we are well aware of the difficulty of mapping velocities to the ionosphere along compressed and disturbed field lines, in presence of very strong, localized, field-aligned currents, this mapping would indicate very high azimuthal (westward) convection velocities of $\sim 4 \mathrm{~km} / \mathrm{s}$ or more. Locally the westward component is particularly high compared to a more averaged convection deduced from SuperDarn radar measurements [Marchaudon, 2003], but such in situ velocities were observed by the past by satellites. For southward IMF $B_{z}$ and IMF $B_{y} \gg 0$ conditions, large spiky poleward directed electric fields, up to $200 \mathrm{mV} / \mathrm{m}$, equivalent to $\sim 4 \mathrm{~km} / \mathrm{s}$, were observed near the low-altitude cusp [Maynard et al., 1991]. Also in the cusp, for IMF $-B_{y} \ll 0$, Wilson and Craven [1999] showed very strong eastward or sunward ion convection velocities, $4-5 \mathrm{~km} / \mathrm{s}$ for $\sim 1 \mathrm{~min}$ intervals. It is clear that the differences in the convection pattern at Cluster and measured in the ionosphere by the SuperDARN are questioning, and this point will be the topic of a future study. We cannot rule out the possibility that the direct mapping may locally have broken down and been violated by the presence of parallel electric fields, time-dependent effects, or distortions in the magnetic field itself by very strong FACs.

[39] To summarize, our simultaneous three-spacecraft detailed observations of the successive $(t 3, t 4, t 5)$ injections seem consistent with the anticipated effects of a patchy reconnection operating for about $10 \mathrm{~min}$ with a repeating rate of $1-3 \mathrm{~min}$. Newly opened flux tubes are appended to each other and their observed properties: ion steps, upward field aligned current sheets (mostly carried by $\sim 10-300 \mathrm{eV}$ precipitating electrons) on the poleward edge, westward plasma flows, are in agreement with the idealized, but elongated, twin vortex pattern presented by Southwood [1987]. Their motion, initially westward, is clearly observed and is fully consistent with the duskward IMF orientation that was prevailing at that time.

\subsection{Inferred Location of the Merging Site}

[40] 3D ion data provided by the CIS instruments can be used to confirm the temporal behavior of the injection process and to infer the distance of the source. Though they include some ambiguities and limitations [see Lockwood and Smith, 1994], various methods have been developed to infer the ion injection location and were recently applied to Cluster data [Vontrat-Reberac et al., 2003]. 


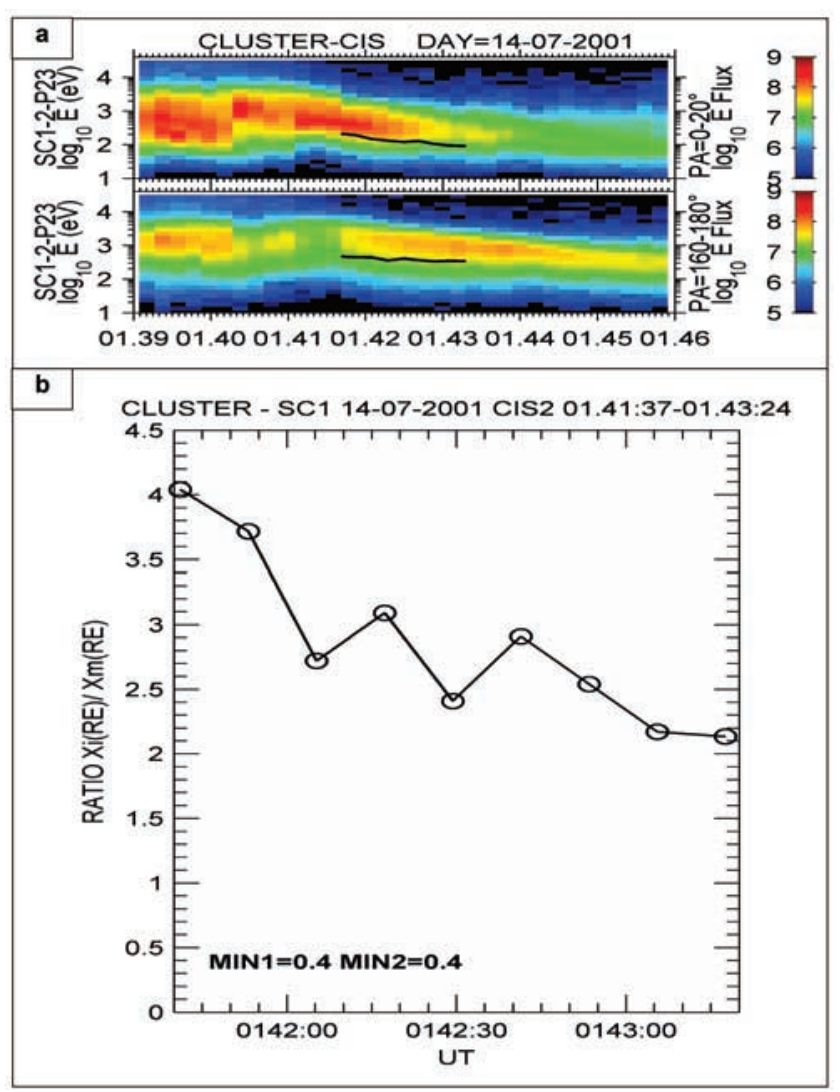

Figure 8. Estimation of the distance of the reconnection site around 0142 UT: (a) SC1 energy-time spectrograms of downward and upward moving ions, for the time period 0139-0146 UT. Low-energy cutoffs of downward and upward moving ions are marked by a black line between 0141:37 and 0143:24 UT (see text for details). (b) Computed $x_{i} / x_{m}$ ratio for all of the $\mathrm{SC} 1$ ion distributions recorded in the time interval. Variables $x_{i}$ and $x_{m}$ are the inferred source distance and the assumed mirroring distance along the magnetic field, respectively.

[41] We again show in Figure 8a the downward and upward SC1 ion spectrograms for the time interval 01390146 UT. Between 0141:38 and 0143:25 UT are superposed the lower-energy interpolated cutoffs (black lines) that are systematically observed for precipitating and mirroring ions. It is noteworthy that at any given time the steadily decreasing mirroring ion energy cutoff is greater than that of the precipitating ions. In the structure stepping at 0140:10 UT, the fluxes of precipitating ions fall near the background at $\sim 0144$ UT while upward flowing ions (PA = $\left.160^{\circ}-180^{\circ}\right)$ can be still observed; these ions were injected before (in time) and eastward (in space) and take longer time to mirror below and reach the spacecraft. This time delay, $\sim 80 \mathrm{sec}$, depending on the pitch angle, gives credence to an interpretation in terms of sporadic, short-lived, ion injections. By performing a time of flight analysis and using these two low-speed cutoffs, Onsager and Fuselier [1994] related the inferred source distance, $x_{i}$, in terms of the assumed mirror-point distance, $x_{m}$, along the magnetic field, and of the two velocity thresholds $v_{i}$ and $v_{m}$ (for pa $=0$ and $180^{\circ}$, respectively), such that $x_{i} / x_{m}=2 \cdot v_{i} /\left(v_{m}-v_{i}\right)$. This ratio was computed for the set of distributions recorded during this time interval and is plotted in Figure $8 \mathrm{~b}$; the individual points are joined for the sake of clarity. The $x_{i} / x_{m}$ ratio is variable but, for a majority of the distributions, it ranges from 2 to 3 . An average $\left\langle x_{i} / x_{m}\right\rangle$ ratio of $\sim 2.5$ would give $x_{i} \sim 10 R_{E}$, assuming all ions mirror at ionospheric altitudes $\left(x_{m} \sim 4 R_{E}\right)$. This result is questionable, as the incoming and mirroring distributions (binned over 31 contiguous energy channels) do not present perfect and sharp $v_{\|}$ low-speed cutoffs. Taking all the uncertainties into account, a source distance of about 7-13 $R_{E}$ from the Cluster position is a reasonable suggestion. Other evaluations, based on the energy-pitch angle dispersion method [Menietti and Burch, 1988; Vontrat-Reberac et al., 2003], would give an identical distance.

[42] In a compressed magnetosphere $\left(P_{s w} \sim 10 \mathrm{nPa}\right)$ and for positive $B_{y}$ conditions (see Figure 1, bent field line at $0140 \mathrm{UT}$ ), the preferential source must be on the duskside of the magnetopause, that is, in the region of preferential antiparallel merging predicted by geometrical models [Crooker, 1979; Luhmann et al., 1984]. MHD global simulations of the present event [Berchem et al., 2003b] effectively confirm this location and demonstrate the complexity of the merging process in this region; details are beyond the scope of this paper and will be reported elsewhere.

[43] The same methods have been applied to the ion injections observed after 0210 UT by the SC3 spacecraft. Low-energy cutoffs between 0212 and 0213 UT indicate a distance $x_{i} \sim 4-5 x_{m} \sim 14-18 R_{E}$ for the reconnection site. Around 0212 UT the ion pressure had returned to its $\sim 5 \mathrm{nPa}$ pre-event level and the magnetopause stand-off distance moved outward, from its compressed position, $\sim 7 R_{E}$, to $9 R_{E}$ We noticed that the bright spot observed by SI-12 was still at the same location 14.0 MLT, $72.5^{\circ}$ MLAT. Thus the larger inferred distance of $\sim 16 R_{E}$, compared to $\sim 10 R_{E}$ at 0140 UT, implies that, in spite of drastic changes in the pressure, the source does not expand or move too much and stays along the flank of the duskward magnetopause. The final injection observed by SC3 occurred at $\sim 0230$ UT. This event followed a turning of the IMF $\left(B_{y} \sim 0, B_{z}<0\right)$, so that the location of the reconnection line must have moved toward the noon sector. A rough evaluation of the reconnection site distance gives an average estimate of $x_{i} \sim$ 2. $x_{m} \sim 8 R_{E}$, that is, near the noon sector. A bright spot was effectively seen around noon by IMAGE.

\subsection{Modulation of the Reconnection Rate by Pressure Changes}

[44] The most remarkable effect demonstrated in this study is the positive correlation evidenced between changes in the solar wind dynamic pressure and the observed ion injections. As we have inferred that such injections are probable signatures of reconnection, the role played by the solar wind pressure in triggering or modulating reconnection pulses must be questioned. In the past authors have shown that this dynamic pressure apparently modulates the rate of reconnection when IMF is southward [Gonzales et $a l ., 1989]$. Alternatively, studies of the high-speed, accelerated flows at the magnetopause reported that reconnection efficiency depended roughly inversely on the local $\beta_{\text {sh }}$ parameter, for $\beta_{s h}>2-5$ [see review by Sonnerup et 


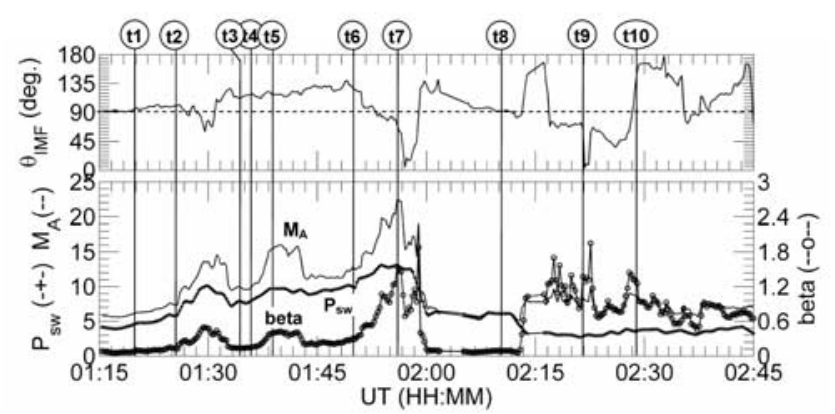

Figure 9. (top) Time-shifted IMF clock angle $\theta_{\mathrm{IMF}}$ and (bottom) solar wind dynamic pressure $P_{s w}$, Afvén Mach number $M_{A s w}$ (left scales) and $\beta$ parameter (right scale).

al., 1995]. On the other hand, Scurry and Russell [1991] showed that $\beta_{s w}, M_{A s w}$, and the fast magnetosonic Mach number, $M_{f m s}$, appeared to have only reduced effects on the "efficiency" of the $3-\mathrm{H}$ averaged signatures of reconnection.

[45] In order to supplement and conclude our analysis, for the 0115-0245 UT time period we superpose in Figure 9 the time-lagged dynamic pressure, $P_{s w}$ the Alfvén Mach number, $M_{A s w}$, the beta parameter, $\beta_{s w}$ (bottom), and the IMF clock angle, $\theta_{\mathrm{IMF}}$ (bottom); again we mark the timing of the successive ion injections observed by Cluster. In computing these plasma parameters we were aware that their values were for the upstream solar wind (at ACE), and not for the magnetosheath region, that is, near the presumable site of reconnection. Aside from variations in the dynamic pressure, the overall period was characterized by a very low solar wind $\beta_{s w}<1.8$, and significant variations in a large $M_{A s w}$ Mach number, characterizing a strong quasiperpendicular bow shock. Basically, a very striking correlation was revealed between the clearer $M_{A s w}$ enhancements and the triggering of individual ion injections, and thus of the inferred pulsed reconnection. Even nonreferenced dispersed substructures or ion steps, for example, around 0130 UT (detected by SC4; see Figure 3), around 0215 UT (detected by SC3; see Figure 3) could be related to these variations. It is also striking that one of referenced structures, t8 at $\sim 0210 \mathrm{UT}$, although possibly related to a significant change in the $\theta_{I M F}$ clock angle, is (within the $23 \mathrm{~min}$ of acceptable error in the lag evaluation) also seemingly related to a sudden increase in $M_{A s w}$. This increase results from a decrease in the magnetic field strength that accompanied a steep increase in the ion temperature. Near the subsolar point Anderson et al. [1997] showed good evidence linking increasing downstream $\beta_{s h}\left(\beta_{s h} \approx 3 / 32 \cdot M_{A s w}^{2} \propto P_{s w} / B_{s w}^{2}\right)$ to decreased reconnection efficiency. Our detailed and injection-byinjection study contrasts with these earlier conclusions and suggests that very large increases in $M_{A s w}$ may play a role in moderating signatures that we interpret as onsets of parallel reconnection near the dusk flank of the magnetosphere.

[46] Our analysis infers the pre-existence of a localized, active (single or multiple) $X$ in the afternoon sector, a region of preferential antiparallel merging, but with a reconnection rate that is activated by drastic changes in the magnetosheath plasma conditions. A possible explanation is that changes in the pressure cause compression of the draped magnetosheath magnetic field together with increases and modulation of the $B_{y}$ component, and therefore favor conditions for merging [Newell and Meng, 1994; Korotova and Sibeck, 1995]. On the other hand, Sandholt et al. [1994] and Farrugia et al. [1995] suggested that a sporadic increase of the dynamic pressure at the magnetopause current sheet could further its decay by reconnection and enhance the rate of reconnection. MHD simulations can be greatly valuable in demonstrating such effects. For instance, 2D MHD simulations [Otto et al., 1995] showed that the impact of pressure perturbations on the magnetopause current layer leads to the onset of magnetic reconnection and can help in the formation of multiple $X$ lines. While our observations are consistent with an active reconnection region located in the dusk sector, remotely it is difficult to find information about the extent of the reconnection region and its exact topology (single $X$ line, multiple $X$ lines). Related global MHD simulations should be very useful in specifying the nature and topology of the newly reconnected field lines. These simulations are presently initiated for the present event, and preliminary results are particularly promising [Berchem et al., 2003a]. The results could be extremely useful in investigating the impact of high-pressure regions and the propagation of surface waves, and in following the reconnection process through for the entire event.

[47] Acknowledgments. We thank CDAWeb for supplying the ACE, Wind, Geotail, and Polar data and N. Ness (Bartol Research Institute), D. J. McComas (SWRI), R. Lepping (NASA/GSFC), K. Ogilvie (NASA/GSFC), T. Mukai (ISIS), and C. T. Russell (UCLA) for providing CDAWeb with key parameters of the ACE magnetic field, ACE plasma, Wind magnetic field, Wind plasma, Geotail plasma, and Polar magnetic field. The event selected for this study was originally chosen and discussed at the second Cluster-ESA Workshop in ESTEC, Noordwijk (March 2002). Contributions by participants M. André, J. Baker, M. Carter, N. Cornilleau-Werhlin, P. Décreau, F. Pitout, P. Quinn, T. Stubbs, and M. Taylor are gratefully acknowledged. We thank the OVT Team (http://ovt.irfu.se) for allowing us to use the Orbit Visualisation Tools. Work at CESR/CNRS and development of the DD_CLUSTER analysis tools (http://goezog.cesr.fr:8080/ DD CLUSTER/) were funded by CNES (French Space Agency). Research at UCLA was supported by NASA grant NGG04GE90G.

[48] Shadia Rifai Habbal thanks Steve E. Milan and another referee for their assistance in evaluating this paper.

\section{References}

Anderson, B., T. Phan, and S. Fuselier (1997), Relationships between plasma depletion and subsolar reconnection, J. Geophys. Res., 102, 9531-9542.

Balogh, A., et al. (2001), The Cluster magnetic field investigation: Overview of in-flight performance and initial results, Ann. Geophys., 19, $1207-1217$.

Berchem, J., S. A. Fuselier, S. Petrinec, H. U. Frey, and J. L. Burch (2003a), Dayside proton aurora: Comparison between global MHD simulations and IMAGE observations, Space Sci. Rev., 109, 313-349.

Berchem, J., J. M. Bosqued, H. U. Frey, and C. P. Escoubet (2003b), Comparison between global MHD simulations and simultaneous Cluster and IMAGE observations of dayside auroral proton precipitation, paper presented at Yosemite 2003: The Dayside Magnetopause and Cusp Conference, NASA, Yosemite, Calif., 10-13 Feb.

Biernat, H., V. Semenov, and R. Rijnbeek (1998), Time-dependent threedimensional Petschek-type reconnection: A case study for magnetopause conditions, J. Geophys. Res., 103, 4693-4706.

Bosqued, J. M., A. Berthelier, J. J. Berthelier, and C. P. Escoubet (1991), A case study of cusp electrodynamics by the Aureol-3 satellite: Evidences for FTE signatures?, Geophys. Res. Lett., 18, 1833-1836.

Bosqued, J. M., et al. (2001), Cluster observations of the high-latitude magnetopause and cusp: Initial results from the CIS ion instruments, Ann. Geophys., 19, 1545-1566.

Coumans, V., J.-C. Gérard, B. Hubert, and D. S. Evans (2002), Electron and proton excitation of the FUV aurora: Simultaneous IMAGE and NOAA 
observations, J. Geophys. Res., 107(A11), 1347, doi:10.1029/ 2001JA009233.

Crooker, N. U. (1979), Dayside merging and cusp geometry, J. Geophys. Res., 84, 951-959.

Dungey, J. W. (1961), Interplanetary magnetic field and the auroral zones, Phys. Rev. Lett., 6, 47-48.

Dunlop, M. W., and T. I. Woodward (1998), Multi-spacecraft discontinuity analysis: Orientation and motion, in Analysis Methods for MultiSpacecraft Data, Sci. Rep. ISSI-SR-001, edited by G. Paschmann and P. Daly, pp. 271-305, Eur. Space Agency, Noordwijk, Netherlands.

Elphic, R. C. (1988), Multipoint observations of the magnetopause: Results from ISEE and AMPTE, Adv. Space Res., 8(9), 223-238.

Elphic, R. C. (1995), Observations of flux transfer events: A review, in Physics of the Magnetopause, Geophys. Monogr. Ser., vol. 90, edited by P. Song, B. U. O. Sonnerup, and M. F. Thomsen, pp. 225-233, AGU, Washington, D. C.

Escoubet, C. P., and J. M. Bosqued (1989), The influence of IMF- $B_{z}$ and/or $A E$ on the polar cusp: An overview of observations from the Aureol-3 satellite, Planet. Space Sci., 37, 609-626.

Escoubet, C. P., M. F. Smith, S. F. Fung, P. C. Anderson, R. A. Hoffman, E. M. Basinska, and J. M. Bosqued (1992), Staircase ion signature in the polar cusp: A case study, Geophys. Res. Lett., 19, 1735-1738.

Escoubet, C. P., J. M. Bosqued, R. A. Hoffman, A. Berthelier, and P. C. Anderson (1997), Opposite ion dispersions observed quasi-simultaneously in the polar cusp by the DE-2 and Aureol-3 satellites, Geophys. Res. Lett., 24, 2487-2490.

Farrugia, C. J., P. E. Sandholt, S. W. H. Cowley, D. J. Southwood, A. Egeland, P. Stauning, R. P. Lepping, A. J. Lazarus, T. Hansen, and E. Friis-Christensen (1995), Reconnection-associated auroral activity stimulated by two types of upstream dynamic pressure variations: Interplanetary magnetic field $B_{z} \sim 0, B_{y} \ll 0$ case, J. Geophys. Res., 100, $21,753-21,772$

Farrugia, C. J., et al. (2004), Pulsed flows at the high-altitude cusp poleward boundary, and associated ionospheric convection and particle signatures, during a Cluster-FAST-SuperDARN-Søndrestrøm conjunction under a southwest IMF, Ann. Geophys., 22, 2891-2905.

Frey, H. U., S. B. Mende, C. W. Carlson, J.-C. Gérard, B. Hubert, J. Spann, R. Gladstone, and T. J. Immel (2001), The electron and proton aurora as seen by IMAGE FUV and FAST, Geophys. Res. Lett., 28, 1135-1138.

Frey, H. U., T. D. Phan, S. A. Fuselier, and S. B. Mende (2003a), Continuous magnetic reconnection at Earth's magnetopause, Nature, 426, 533-537, doi: $10.1038 /$ nature 02084.

Frey, H. U., S. B. Mende, T. J. Immel, J.-C. Gérard, B. Hubert, S. Habraken, J. Spann, G. R. Gladstone, D. V. Bisikalo, and V. I. Shematovich (2003b), Summary of quantitative interpretation of IMAGE far ultraviolet auroral data, Space Sci. Rev., 109, 255-283.

Frey, H. U., S. B. Mende, S. A. Fuselier, T. J. Immel, and N. Østgaard (2003c), Proton aurora in the cusp during southward IMF, J. Geophys. Res., 108(A7), 1277, doi:10.1029/2003JA009861.

Gérard, J.-C., B. Hubert, D. V. Bisikalo, and V. I. Shematovich (2000), A model of the Lyman $\alpha$ line profile in the proton aurora, J. Geophys. Res., $105,15,795-15,806$.

Gérard, J.-C., B. Hubert, M. Meurant, V. I. Shematovich, D. V. Bisikalo, H. Frey, S. Mende, G. R. Gladstone, and C. W. Carlson (2001), Observation of the proton aurora with IMAGE FUV imager and simultaneous ion flux in situ measurements, J. Geophys. Res., 106, 28,939-28,948.

Gonzales, W. D., B. T. Tsurutani, A. L. C. Gonzales, E. J. Smith, F. Tang, and S. I. Akasofu (1989), Solar-wind-magnetosphere coupling during intense substorms (1978-1979), J. Geophys. Res., 94, 8835-8851.

Gustafsson, G., et al. (2001), First results of electric field and density observations by Cluster EFW based on initial months of operation, Ann. Geophys., 19, 1219-1240.

Haerendel, G., G. Paschmann, N. Sckopke, H. Rosenbauer, and P. C. Hedgecock (1978), The frontside boundary layer of the magnetosphere and the problem of reconnection, J. Geophys. Res., 83, 3195-3216.

Jacobsen, B., P. E. Sandholt, W. J. Burke, W. F. Denig, and N. C. Maynard (1995), Optical signatures of prenoon auroral precipitation: Sources and responses to solar wind variations, J. Geophys. Res., 100, 8003-8012.

Johnstone, A. D., et al. (1997), PEACE: A plasma electron and current experiment, Space Sci. Rev., 79, 351-398.

Korotova, G., and D. Sibeck (1995), A case study of transient event motion in the magnetosphere and in the ionosphere, J. Geophys. Res., $100,35-46$.

Lavraud, B., et al. (2005), Cluster observes the high-altitude cusp region, Surv. Geophys., in press.

Lockwood, M. (1991), Flux transfer events at the dayside magnetopause: Transient reconnection or magnetosheath dynamic pressure pulses?, J. Geophys. Res., 96, 5497-5509.

Lockwood, M. (1995), Ground-based and satellite observations of the cusp: Evidence for pulsed magnetopause reconnection, in Physics of the Mag- netopause, Geophys. Monogr. Ser., vol. 90, edited by P. Song, B. U. O. Sonnerup, and M. F. Thomsen, p. 417-426, AGU, Washington, D. C. Lockwood, M., and C. J. Davis (1996), On the longitudinal extent of magnetopause reconnection pulses, Ann. Geophys., 14, 865-878.

Lockwood, M., and M. F. Smith (1992), The variation of reconnection rate at the dayside magnetopause and cusp ion precipitation, J. Geophys. Res., 97, 14,841-14,847.

Lockwood, M., and M. Smith (1994), Low and middle altitude cusp particle signatures for general magnetopause reconnection rate variations: 1 . Theory, J. Geophys. Res., 99, 8531-8554.

Lockwood, M., C. J. Davis, T. G. Onsager, and J. A. Scudder (1998), Modeling signatures of pulsed magnetopause reconnection in cusp ion dispersion signatures seen at middle altitudes, Geophys. Res. Lett., 25, $591-594$

Lockwood, M., et al. (2001a), Coordinated Cluster, ground-based instrumentation and low-altitude satellite observations of transient polewardmoving events in the ionosphere and in the tail lobe, Ann. Geophys., 19, $1589-1612$.

Lockwood, M., et al. (2001b), Coordinated Cluster and ground-based instrument observations of transient changes in the magnetopause boundary layer during an interval of predominantly northward IMF: Relation to reconnection pulses and FTE signatures, Ann. Geophys., 19, 1613-1640.

Lockwood, M., S. Milan, T. Onsager, C. Perry, J. Scudder, C. Russell, and M. Brittnacher $(2001 \mathrm{c})$, Cusp ion steps, field-aligned currents and poleward moving auroral forms, J. Geophys. Res., 106, 29,555-29,570.

Lockwood, M., B. S. Lanchester, H. U. Frey, K. Throp, S. K. Morley, S. E. Milan, and M. Lester (2003), IMF control of cusp proton emission intensity and dayside convection: Implications for component and antiparallel reconnection, Ann. Geophys., 21, 955-982.

Luhmann, J. G., R. J. Walker, C. T. Russell, N. U. Crooker, J. R. Spreiter, and S. S. Stahara (1984), Patterns of potential magnetic field merging sites on the dayside magnetopause, J. Geophys. Res., 89, 1739-1742.

Marchaudon, A. (2003), Etude multi-instruments de la dynamique des structures aurorales côté jour et côté nuit: Couplage avec la magnétosphère et le milieu interplanétaire (in French), Ph.D. thesis, VersaillesSaint-Quentin Univ., Versailles, France.

Marchaudon, A., J.-C. Cerisier, J.-M. Bosqued, M. W. Dunlop, J. A. Wild, P. M. E. Décréau, M. Förster, D. Fontaine, and H. Laakso (2004), Transient plasma injections in the dayside magnetosphere: One-to-one correlated observations by Cluster and SuperDARN, Ann. Geophys., 22, 141-158.

Maynard, N., T. Aggson, E. Basinska, W. Burke, P. Craven, W. Peterson, M. Sugiura, and D. Weimer (1991), Magnetospheric boundary dynamics: DE 1 and DE 2 observations near the magnetopause and cusp, J. Geophys. Res., 96, 3505-3522.

McWilliams, K. A., T. K. Yeoman, and S. W. H. Cowley (2001), Twodimensional electric field measurements in the ionosphere footprint of a flux transfer event, Ann. Geophys., 18, 1584-1598.

Mende, S. B., et al. (2000), Far ultraviolet imaging from the IMAGE spacecraft: 3. Spectral imaging of Lyman $\alpha$ and OI $135.6 \mathrm{~nm}$, Space Sci. Rev., 91, 287-318.

Menietti, J., and J. Burch (1988), Spatial extent of the plasma injection region in the cusp-magnetosheath interface, J. Geophys. Res., 93, 105-113.

Milan, S. E., M. Lester, S. W. H. Cowley, and M. Brittnacher (2000), Convection and auroral response to a southward turning of the IMF: PolarUVI, CUTLASS and IMAGE signatures of transient magnetic flux transfer at the magnetopause, J. Geophys. Res., 105, 15,741-15,755.

Newell, P. T., and C.-I. Meng (1991), Ion acceleration at the equatorward edge of the cusp: Low-altitude observations of patchy merging, Geophys. Res. Lett., 18, 1829-1832.

Newell, P., and C.-I. Meng (1994), Ionospheric projections of magnetospheric regions under low and high solar wind pressure conditions, J. Geophys. Res., 99, 273-286.

Onsager, T. G., and S. A. Fuselier (1994), The location of magnetopause reconnection for northward and southward interplanetary magnetic field, in Solar System Plasmas in Space and Time, Geophys. Monogr. Ser., vol. 84, edited by J. L. Burch and J. H. Waite, pp. 183-197, AGU, Washington, D. C.

Opgenoorth, H. J., et al. (2001), Coordinated ground-based, low altitude satellite and Cluster observations on global and local scales during a transient post-noon sector excursion of the magnetospheric cusp, Ann. Geophys., 19, 1367-1398.

Otto, A., L. C. Lee, and Z. W. Ma (1995), Magnetic field and plasma properties associated with pressure pulses and magnetic reconnection at the dayside magnetopause, J. Geophys. Res., 100, 14,895-14,912.

Phan, T., et al. (2003), Simultaneous Cluster and IMAGE observations of cusp reconnection and auroral proton spot for northward IMF, Geophys. Res. Lett., 30(10), 1509, doi:10.1029/2003GL016885.

Provan, G., T. K. Yeoman, and S. E. Milan (1998), CUTLASS Finland radar observations of the ionospheric signatures of flux transfer events and the resulting plasma flows, Ann. Geophys., 16, 1411-1422. 
Reiff, P. H., T. W. Hill, and J. L. Burch (1977), Solar wind plasma injection at the dayside magnetospheric cusp, J. Geophys. Res., 82, 479-491.

Rème, H., et al. (2001), First multispacecraft ion measurements in and near the Earth's magnetosphere with the identical Cluster ion spectrometry (CIS) experiment, Ann. Geophys., 19, 1303-1354.

Russell, C. T., and R. C. Elphic (1978), Initial ISEE magnetometer results: Magnetopause observations, Space Sci. Rev., 22, 681-715.

Russell, C. T., and R. C. Elphic (1979), ISEE observations of flux transfer events at the dayside magnetopause, Geophys. Res. Lett., 6, 33-36.

Sandholt, P. E., and C. J. Farrugia (2003), Does the aurora provide evidence for the occurrence of antiparallel magnetopause reconnection?, J. Geophys. Res., 108(A12), 1466, doi:10.1029/2003JA010066.

Sandholt, P. E., et al. (1994), Cusp/cleft auroral activity in relation to solar wind dynamic pressure, IMF $B_{z}$ and $B_{y}, J$. Geophys. Res., 99, 17,32317,342 .

Sanny, J., D. Sibeck, C. Venturini, and C. Russell (1996), A statistical study of transient events in the outer dayside magnetosphere, J. Geophys. Res., $101,4939-4952$.

Scurry, L., and C. T. Russell (1991), Proxy studies of energy transfer to the magnetosphere, J. Geophys. Res., 96, 9541-9548.

Shue, J.-H., et al. (1998), Magnetopause location under extreme conditions, J. Geophys. Res., 103, 17,691-17,700.

Sibeck, D. G. (1990), A model for the transient magnetospheric response to sudden solar wind dynamic pressure variations, J. Geophys. Res., 95 , $3755-3771$.

Sibeck, D. G. (1992), Transient events in the outer magnetosphere: Boundary waves or flux transfer events?, J. Geophys. Res., 97, 4009-4026.

Song, P., G. Le, and C. T. Russell (1994), Observational differences between flux transfer events and surface waves at the magnetopause, J. Geophys. Res., 99, 2309-2320.

Sonnerup, B. U. Ö., G. Passchmann, and T. D. Phan (1995), Fluid aspects of reconnection at the magnetopause: In situ observations, in Physics of the Magnetopause, Geophys. Monogr. Ser, vol. 90, edited by P. Song, B. U. O. Sonnerup, and M. F. Thomsen, p. 167-180, AGU, Washington, D. C.

Southwood, D. J. (1987), The ionospheric signature of flux transfer events, J. Geophys. Res., 92, 3207-3213.

Trattner, K. J., S. A. Fuselier, W. K. Peterson, and C. W. Carlson (2002), Spatial features observed in the cusp under steady solar wind conditions, J. Geophys. Res., 107(A10), 1288, doi:10.1029/2001JA000262.

Trattner, K. J., et al. (2003), Cusp structures: Combining multi-spacecraft observations with ground-based observations, Ann. Geophys., 21, 2031 2041.

Tsyganenko, N. A. (2002), A model of the near magnetosphere with a dawn-dusk asymmetry: 2. Parameterization and fitting to observations, J. Geophys. Res., 107(A7), 1176, doi:10.1029/2001JA000220.

Vontrat-Reberac, A., J. M. Bosqued, M. G. G. T. Taylor, B. Lavraud, D. Fontaine, M. W. Dunlop, H. Laakso, N. Cornilleau-Werhlin, P. Canu, and A. Fazakerley (2003), Cluster observations of the high-altitude cusp for northward interplanetary magnetic field: A case study, J. Geophys. Res., 108(A9), 1346, doi:10.1029/2002JA009717

Wild, J. A., et al. (2001), First simultaneous observations of flux transfer events at the high-latitude magnetopause by the Cluster spacecraft and pulsed radar signatures in the conjugate ionosphere by the CUTLASS and EISCAT radars, Ann. Geophys., 19, 1491-1508.

Wild, J. A., et al. (2003), Coordinated inter hemispheric SuperDARN radar observations of the ionospheric response to flux transfer events observed by the Cluster spacecraft at the high-latitude magnetopause, Ann. Geophys., 21, 1807-1826.

Wild, J. A., et al. (2005), Simultaneous in-situ observations of the signatures of dayside reconnection at the high and low latitude magnetopause, Ann. Geophys., 23, 445-460.

Wilson, G. R., and P. Craven (1999), Molecular ion upflow in the cleft ion fountain, J. Geophys. Res., 104, 4437-4446.

Wing, S., P. Newell, and J. Ruohoniemi (2001), Double cusp: Model prediction and observational verification, J. Geophys. Res., 106, 25,57125,594

Zhou, X., C. Russell, G. Le, and N. Tsyganenko (1997), Comparison of observed and model magnetic fields at high altitudes above the polar cap: POLAR initial results, Geophys. Res. Lett., 24, 1451-1454.

A. Balogh, Space and Atmospheric Physics Group, Blackett Laboratory, Imperial College, Prince Consort Road, London SW7 2BZ, UK.

J. Berchem, IGPP, UCLA, Slichter Hall, 405 Hilgard Avenue, Los Angeles, CA 90095-1567, USA

J. M. Bosqued, E. Budnik, and H. Rème, CESR/CNRS, 9 Avenue Colonel Roche, BP 4346, F-31028 Toulouse Cedex 4, France. (bosqued@ cesr.fr)

J. C. Cerisier, Centre d'Etude des Environnements Terrestre et Planétaires, 4 Avenue de Neptune, F-94107 Saint-Maur-des-Fossés Cedex, France.

M. Dunlop, Space Science and Technology Department, Rutherford Appleton Laboratory, Chilton, Didcot OX11 0QX, UK.

C. P. Escoubet and H. Laakso, Space Science Department, ESA/ESTEC, PostBus 299, Keplerlaan, 1, NL-2200 AG Noordwijk, Netherlands.

A. Fazakerley and A. Marchaudon, Mullard Space Science Laboratory, University College London, Holmbury St. Mary, Dorking, Surrey RH5 6NT, UK.

H. U. Frey, Space Sciences Laboratory, University of California, Grizzly Peak Blvd., Berkeley, CA 94720, USA.

B. Lavraud, Space and Atmospheric Sciences, Los Alamos National Laboratory, MS D466, Los Alamos, NM 87545, USA 